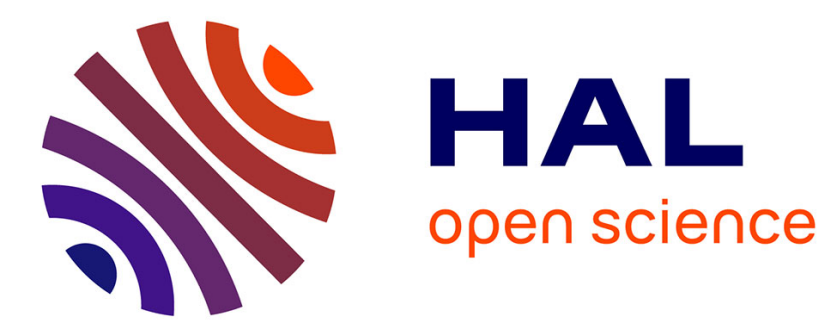

\title{
Present-day gully activity in Sisyphi Cavi, Mars -Flow-like features and block movements
}

\author{
Jan Raack, Susan J. Conway, Thomas Heyer, Valentin Tertius Bickel, Meven \\ Philippe, Harald Hiesinger, Andreas Johnsson, Marion Massé
}

\section{To cite this version:}

Jan Raack, Susan J. Conway, Thomas Heyer, Valentin Tertius Bickel, Meven Philippe, et al.. Presentday gully activity in Sisyphi Cavi, Mars -Flow-like features and block movements. Icarus, 2020, 350, pp.113899. 10.1016/j.icarus.2020.113899 . hal-02989781

\section{HAL Id: hal-02989781 \\ https://hal.science/hal-02989781}

Submitted on 5 Nov 2020

HAL is a multi-disciplinary open access archive for the deposit and dissemination of scientific research documents, whether they are published or not. The documents may come from teaching and research institutions in France or abroad, or from public or private research centers.
L'archive ouverte pluridisciplinaire HAL, est destinée au dépôt et à la diffusion de documents scientifiques de niveau recherche, publiés ou non, émanant des établissements d'enseignement et de recherche français ou étrangers, des laboratoires publics ou privés. 
3 Jan Raack ${ }^{\mathrm{a}}$, Susan J. Conway ${ }^{\mathrm{b}}$, Thomas Heyer ${ }^{\mathrm{a}}$, Valentin T. Bickel ${ }^{\mathrm{c}, \mathrm{d}}$, Meven Philippe ${ }^{\mathrm{b}}$, Harald

$4 \quad$ Hiesinger $^{\mathrm{a}}$, Andreas Johnsson ${ }^{\mathrm{e}}$, Marion Massé ${ }^{\mathrm{b}}$

5

6 Institut für Planetologie, Westfälische Wilhelms-Universität Münster, Wilhelm-Klemm-Str. 10,

$7 \quad 48149$ Münster, Germany

8 baboratoire de Planétologie et Géodynamique, UMR 6112, CNRS, Université de Nantes, 2

9 chemin de la Houssinière, BP 92205, 44322 Nantes Cedex 3, France

10 cDepartment Planets and Comets, Max Planck Institute for Solar System Research, Justus-von-

11 Liebig-Weg 3, 37077 Göttingen, Germany

12 d Department of Earth Sciences, ETH Zurich, Sonneggstrasse 5, 8092 Zurich, Switzerland

13 e Department of Earth Sciences, University of Gothenburg, Box 460, Gothenburg SE-405 30,

14 Sweden

15

16 Keywords: Mars; Mars, surface; Geological processes; Photometry; Mars, climate; Mars, polar

17 geology; Ices

18

19

20

21

22

23 


\section{Abstract}

25 The continuously increasing number of multi-temporal high-resolution images from the surface of Mars offers the possibility for detailed studies of present-day surface activity. In this study we

27 investigated all gullies in the Sisyphi Cavi region $\left(355^{\circ} \mathrm{E}, 71^{\circ} \mathrm{S}\right)$ of the south polar region of Mars. This region is influenced by the seasonal deposition of a decimeters-thick translucent slab ice in

29 late autumn/winter and its subsequent sublimation in spring. We mapped all gullies $(\mathrm{n}=17.760)$ and measured their orientations. We also identified gullies with contemporary activity $(\mathrm{n}=35)$ using multi-temporal HiRISE images for martian years (MY) 28 to 34. We observed two different kinds of activity: (1) dark flow-like features, and (2) movement of blocks. For both, sediment was transported from the source region (alcove and/or flanks of channels) down the gully. Using image data from HRSC, CTX, and HiRISE, we monitored the general defrosting of the study region. We also analyzed the maximum daytime surface temperatures of the complete study region based on TES data from MYs 24 to 26. To identify the origin and triggering mechanism of the observed activity, we used: (1) detailed topographic investigations (e.g., slope angles) of two extensively gullied slopes based on two HiRISE-DTMs, (2) identification of small scale displacements with

Digital Image Correlation (DIC), and (3) orientation measurements of active gullies and comparison to non-active gullies.

41 We found that for the active gullies studied, activity happens at the end of spring between Ls $\sim 225^{\circ}$

42 and $\sim 250^{\circ}$. This is consistent with the timing of final stages of defrosting in the region. At this 43 time, some surfaces are already defrosted while others still host the seasonal slab ice cover. For 44 the surfaces with slab ice, dark defrosting spots (and flows, if the surface is inclined) are observed on dark dunes as well as on gully aprons and in gully channels. These spots form when, triggered 46 by basal sublimation generated overpressure, sediment entrained in $\mathrm{CO}_{2}$-gas is transported through 
47 cracks within the ice and redeposited onto the frosted surface. We compared and linked both

48 morphologic features (dark dune spots and dark flow-like features) and concluded that these

49 features have comparable or even the same triggering mechanisms. Based on this extensive study,

50 the most plausible mechanism for ongoing gully activity can be divided into two steps: 1)

51 accumulation of material within gully channels via small dry flows on top of the slab ice

52 (comparable to dark dune spots/flows), 2) when a critical mass is reached, the sediment flows

53 down the still frosted gully on top of the sublimating ice or as a mixture of dry material and ice in

54 a catastrophic flow. The triggering factor for the movement of blocks remains unclear, as their

55 timing could not be constrained with the available data. We identified headwall erosion in one

56 gully in the study region, whereas a discrete source could not be identified for the other sites,

57 suggesting multiple failure mechanisms could be active in such gullies. Finally, through volume

58 balance calculations we show that active gullies in Sisyphi Cavi could have been formed within

59 decades to several tens of thousands of MY, but gully-morphology indicates a much-longer period

60 for formation of the entire gully-landform.

61

\section{Introduction}

63 Gullies on Mars are features comprised of an alcove, channel, and debris apron and can range up 64 to several kilometers in length (Malin and Edgett, 2000; Figure 1). They are found on steep slopes 65 in the mid to high latitudes of Mars and have a wide range of morphologies (e.g., Dickson et al., 66 2007; Dickson and Head, 2009; Conway et al., 2011, 2015; Harrison et al., 2015). They were

67 initially thought to originate from erosion and deposition of sediments by flowing liquid water, in 68 a similar fashion to gullies on Earth (Malin and Edgett, 2000). 
An alternate hypothesis, proposed shortly after the discovery of gullies, is that $\mathrm{CO}_{2}$ could play a role in triggering sediment motion that forms gullies (Musselwhite et al., 2001; Hoffman, 2002). $\mathrm{CO}_{2}$ ice is deposited on the martian surface every winter, forming a continuous layer down to $\sim 50^{\circ}$

72 in both hemispheres and a discontinuous layer down to $30^{\circ}$ latitude (Piqueux et al., 2003;

73 Schorghofer and Edgett, 2006; Vincendon et al., 2010a, 2010b; Pilorget et al., 2011) mirroring the

74 latitudinal distribution of gullies. The $\mathrm{CO}_{2}$ hypothesis was initially proposed based on the presence 75 of gullies located near the south pole of Mars where annual $\mathrm{CO}_{2}$ frost deposits would be at their 76 thickest (Hoffman, 2002; Ishii and Sasaki, 2004; Cedillo-Flores et al., 2011) and where surface 77 temperatures are too low to support the presence of liquid water. The mechanism proposed by and Nimmo, 2002). Ishii and Sasaki (2004) and Ishii et al. (2006) proposed that gullies could be

81 formed by $\mathrm{CO}_{2}$ ice avalanches and Hugenholtz (2008) slightly modified this idea by suggesting $82 \mathrm{CO}_{2}$ ice coated grains could avalanche by vaporization of the $\mathrm{CO}_{2}$ frost. Cedillo-Flores et al. (2011) 83 proposed a mechanism by which dust or sand superposed onto a $\mathrm{CO}_{2}$ ice surface would be mobilized by sublimation of the underlying $\mathrm{CO}_{2}$ ice. Pilorget and Forget (2016) suggested that martian gullies could result from basal $\mathrm{CO}_{2}$ sublimation of an ice layer and subsequent movement 86 of material underneath the $\mathrm{CO}_{2}$ ice layer.

87 Ongoing observations of gully activity at the present-day have continued to raise questions, not 88 only regarding the formation mechanisms of gullies, but also the triggering mechanisms of the 89 activity (Malin et al., 2006; McEwen et al., 2007a; Diniega et al., 2010; Dundas et al., 2010, Reiss et al., 2010, Dundas et al., 2012; Jouannic et al., 2012; Dundas et al., 2015; Raack et al., 2015; 91 Pasquon et al., 2016; Dundas et al., 2019; Pasquon et al., 2019a, 2019b). Recent laboratory 
92 experiments under martian atmospheric conditions have shown that unstable water on the martian

93 surface could have an influence on the formation of recent and present-day mass wasting features

94 (Raack et al., 2017; Herny et al., 2019), but the climatic conditions (e.g., low surface temperatures)

95 at times when gully activity occurs on Mars makes water-triggered activity very unlikely. As a

96 consequence, the focus of research has moved from $\mathrm{H}_{2} \mathrm{O}$ - to $\mathrm{CO}_{2}$-related mechanisms when

97 investigating contemporary gully activity, but all three possible triggering factors $\left(\mathrm{H}_{2} \mathrm{O}, \mathrm{CO}_{2}\right.$ and

98 dry or possible combinations) should continue to be considered for active gullies on Mars.

99 This study focuses on polar pit gullies, which were the focus of the initial studies referring to $\mathrm{CO}_{2}$

100 frost as the mechanism behind martian gullies. Our objective is to exploit all available imaging

101 data to identify and catalogue the types, timing, and frequency of present-day activity in these

102 gullies with the aim to provide insights into the processes driving this activity. We also investigate

103 whether the present-day processes could account for the presence and morphology of all the gullies

104 in the south-polar pits or whether other mechanisms need to be invoked. Furthermore, the polar

105 location of the gullies investigated in this study combined with the polar orbits of the main imaging

106 orbiters means that there is a higher frequency of observations compared to gullies at lower

107 latitudes, providing a unique opportunity to study the activity of gullies in detail. 


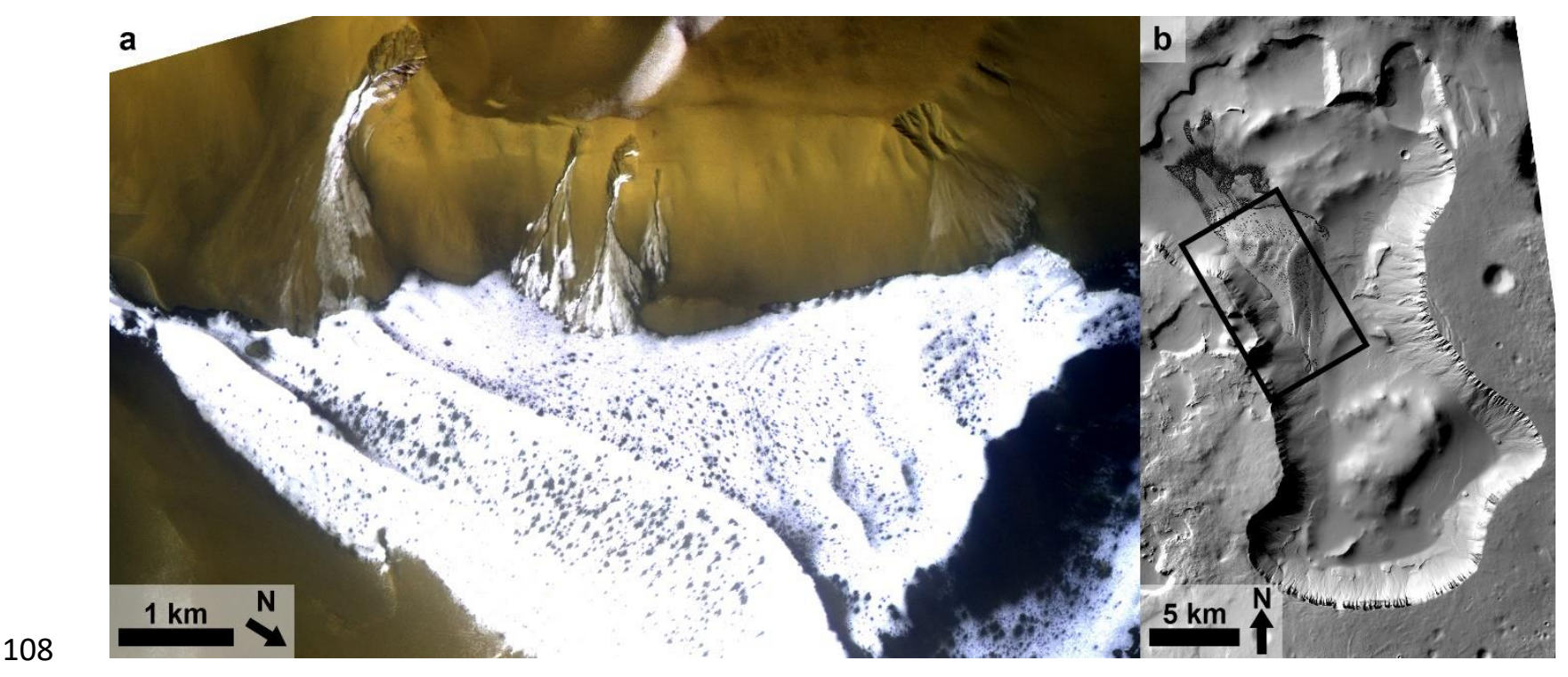

Figure 1: (a) Color and Stereo Surface Imaging System (CaSSIS) image (Thomas et al., 2017) of a gullied slope within the study region. The gullies are the same as those presented in Figure 14.

111 Bright surfaces correspond to the annually deposited $\mathrm{CO}_{2}$ surface frost cover. This image was 112 acquired at the end of spring when the general defrosting of the study region was already well113 advanced. $\mathrm{CO}_{2}$ surface frosts are only visible on the large dark dune, which is completely covered 114 with a bright ice cover, and on gully aprons / alcoves. Dark spots on the dune show slight flow115 like streaks where the slope is highest (on the lower part of the dune). Image (MY34_003464_256_1) was acquired in MY 34 at Ls 242 , flow direction is from top to bottom.

117 (b) Context image of the complete gullied region (Region 5, see Figure 2). Image was acquired in MY 30 at Ls $201^{\circ}$ (CTX-image G06_020600_1115) where surface frost covers the complete region and first dark spots on the dune and defrosting of gully alcoves at the north-facing (equatorfacing) slope are visible. The black frame represents the location of the CaSSIS image. 


\section{Study region}

125 The study region comprises the complete Sisyphi Cavi region, an area with numerous polar pits 126 (depressions) up to $\sim 1 \mathrm{~km}$ deep (Tanaka and Scott, 1987). Sisyphi Cavi is named after "Sisyphus", 127 the ancient king of Ephyra. In Greek mythology, Sisyphus was punished in the underworld after 128 his death. He had to roll a large boulder up a steep hill, but each time just before reaching the top 129 of the hill, the boulder would roll down again and he would have to start again. This frustrating 130 punishment including rolling boulders turns out to be surprisingly relevant to this work and shows 131 the name was well-chosen (see Section 3.1.2).

132 The formation of these irregular steep-sided polar pits in general and specifically in this region is not well understood. The pits are incised into relatively smooth upland surfaces of Amazonian age

134 (Tanaka and Scott, 1987) and some layering is visible at their slopes. There are two large regions 135 with polar pitted terrain (Angusti Cavi at $\sim 290^{\circ} \mathrm{E}$ and $\sim 77^{\circ} \mathrm{S}$; Sisyphi Cavi at $\sim 355^{\circ} \mathrm{E}$ and $\sim 71^{\circ}$

136 S) near the south pole, which were first noticed on Mariner 9 images and described by Murray et 137 al. (1972) and Sharp (1973) as eolian erosion (denudation) of sedimentary rocks of eolian or 138 volcanic origin. Later, Howard (1981) raised the hypothesis that basal melting of ground ice 139 formed these pits, which was supported by Thomas et al. (1992) who reported that the region 140 consists of volatile-rich polar cap deposits, and by Head (2000) and Ghatan and Head (2002). The 141 basal melting is believed to have been brought about by increased geothermal heat flux in the 142 vicinity of subglacial volcanoes located in the eastern part of Sisyphi Cavi (Ghatan and Head, 143 2002).

144 No matter of their origin, the pits of the Sisyphi Cavi form steep slopes in the polar regions. Gullies 145 form preferentially on steep slopes (Conway et al., 2019) so this is one of two polar concentrations 146 of gullies in the southern hemisphere, the other being Angusti Cavi. We defined our study region 
147 from $-66^{\circ}$ to $-76^{\circ} \mathrm{S}$ and from $340^{\circ}$ to $10^{\circ} \mathrm{E}$ in which nearly all the pits in Sisyphi Cavi were 148 covered (Figure 2). Raack et al. (2015) were the first to study the activity of gullies in Sisyphi Cavi 149 in detail. One of their gullies showed signs of activity every Mars year (MY) during their 150 observation phase between MYs 29 and 31 and was analyzed in detail. Raack et al. (2015) found 151 that sediments were transported down the gully and deposited over and next to the apron. Gully 152 activity appeared during mid-spring when surface temperatures began to rise and the seasonal 153 surface ice sublimated. Based on spectral observations and numerical modeling, the surface ice 154 was identified as $\mathrm{CO}_{2}$ translucent slab ice with minor contaminations of $\mathrm{H}_{2} \mathrm{O}$ ice. The most 155 plausible mechanism for the observed activity were dry flows mobilized over the sublimating $\mathrm{CO}_{2}$ 156 ice surface (e.g., Cedillo-Flores et al., 2011). The material for the dry flows was most likely to 157 originate from the slopes of the gully channel, triggered by sublimation. Our here presented work 158 includes the active gully analyzed by Raack et al. (2015) and adds new insights based on newly 159 available high-resolution datasets.

160 Studies of gully activity by Dundas et al. $(2012,2015,2019)$ also included the Sisyphi Cavi gullies.

161 Dundas et al. $(2012,2015,2019)$ noted activity in them but made no detailed specific morphologic 162 observations. In a study of the topographic long profiles of gullies on Mars, Conway et al. (2015) 163 found that gullies in the polar pits had shallower slopes than those elsewhere and that they had 164 generally a more pronounced curvature. Gullies in Sisyphi Cavi can be named to be "classic 165 gullies" with a distinct alcove, channel, and apron system. 


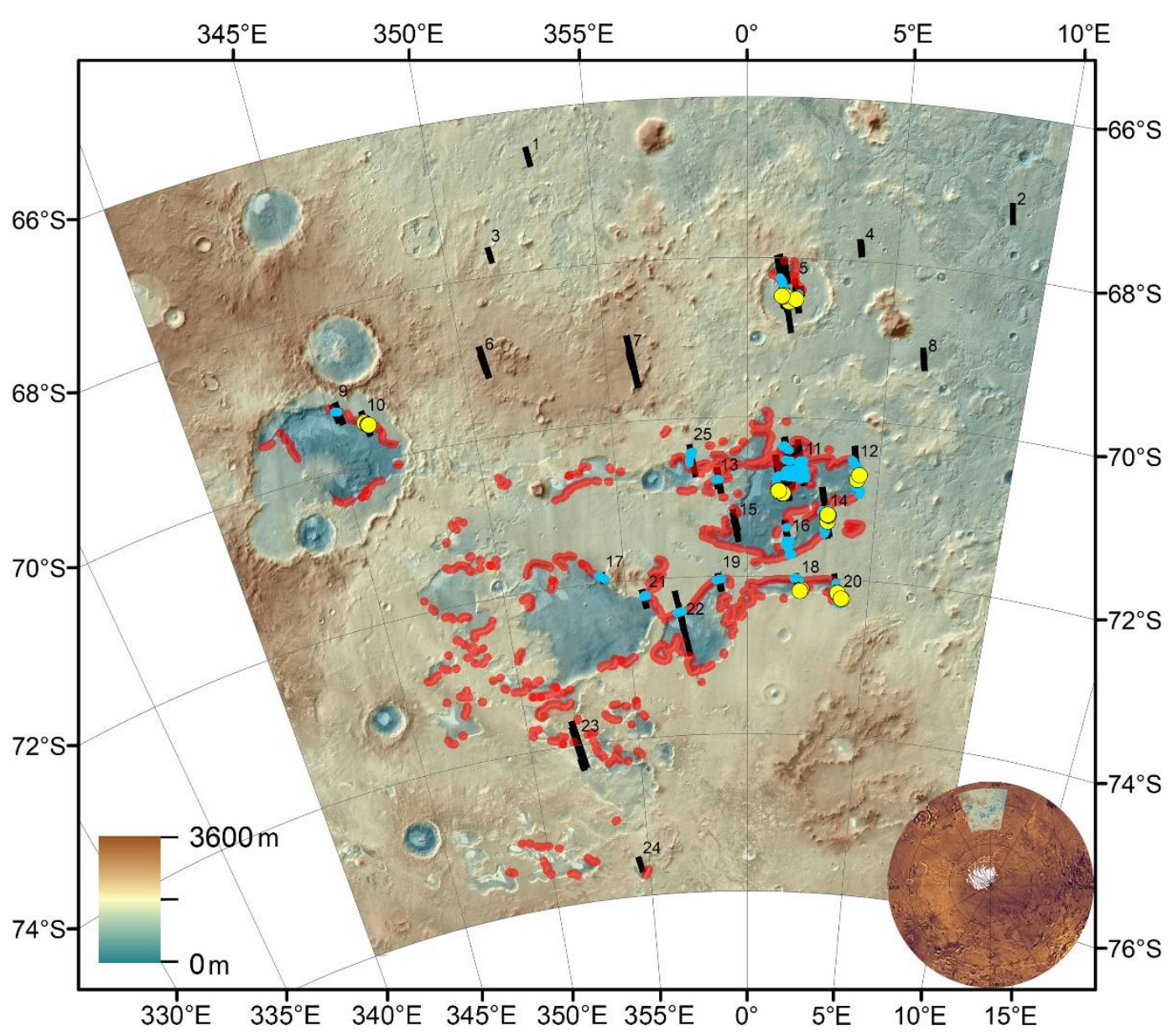

167 Figure 2: THEMIS-IR data superposed by a MOLA digital terrain model (DTM) of the study 168 region, which comprises the complete Sisyphi Cavi region. Multi-temporal HiRISE image 169 footprints are represented by black rectangles, numbered from north (1) to south (24), except (25)

170 because these multi-temporal datasets were acquired after the begin of our study. These footprints 171 (25) can be found in the middle of the study region. These numbers represent the 25 individual 172 multi-temporal covered study regions which were investigated. Gully activity was found in seven 173 of them $(5,10,11,12,14,18,20$, see yellow dots). Red dots represent mapped gullies based on 174 CTX imagery $(\mathrm{n}=17,760)$, blue dots represent mapped gullies on multi-temporal HiRISE imagery $175(\mathrm{n}=2,067)$, yellow dots represent contemporary active gullies $(\mathrm{n}=35)$ identified on multi176 temporal HiRISE images. 


\section{Data and methods}

\subsection{Datasets}

We used different visual and thermal datasets for our study of active gullies and the defrosting within the study region. For a general overview, context, and topographic information, we used Thermal Emission Imaging System daytime infrared (THEMIS-IR) (Christensen et al., 2004) data combined with a Mars Orbiter Laser Altimeter digital terrain model (MOLA DTM) (Zuber et al., 1992). MOLA polar gridded data (460 m/pix) were used for slope orientation measurements. Furthermore, 28 High Resolution Stereo Camera (HRSC) images (at approximately 12.5 m/pixel, Jaumann et al., 2007) were also used for a general overview of the study region and for frost identification during spring, as a validation of observations with the Context Camera (CTX). CTX images (Malin et al., 2007) were used for mapping and orientation measurements of all gullies and gullied slopes, as well as for identification of defrosting in the entire study region. We used 382 CTX images with a resolution of $\sim 5 \mathrm{~m} /$ pixel. Furthermore, we used a CTX mosaic provided by Dickson et al. (2018) as a basis for the mapping of all gullies in the study region. For detailed and multi-temporal investigations, we analyzed 212 multi-temporal (with a coverage of at least two images of same area) High Resolution Imaging Science Experiment (HiRISE) images with a resolution between 0.25 and $1 \mathrm{~m} /$ pixel (McEwen et al., 2007b). Two Colour and Stereo Surface Imaging System (CaSSIS) images (Thomas et al., 2017) were used for a color overview of frostcovered gullied slopes.

Visual datasets were identified using the MUTED webtool (Heyer et al., 2018), which provides a direct download link to the PDS Geoscience Node (http://pdsgeosciences.wustl.edu/dataserv/mars.html). CTX and HiRISE images were downloaded as a preprocessed product for direct integration into an ESRI ArcGIS project. Possible necessary 
adjustments of the exact location and perfect co-registration of multi-temporal datasets were done

201

202

203

204

205

206

207

208

209

210

211 approximately

September

212 (https://www.jpl.nasa.gov/releases/2001/duststorm_010709.html

https://mars.nasa.gov/resources/7886/dust-storms-of-2001/). During this time, the instrument was

214 not able to collect reliable data and surface temperatures were not usable for our study.

215 Consequently, we did not take the data from MY 25 at Ls $185^{\circ}$ to $\mathrm{Ls} 260^{\circ}\left(\sim 26^{\text {th }}\right.$ June to $\sim 27^{\text {th }}$

216 October 2001) into account. In general, TES data were acquired in earlier martian years (MY 24

217 to 26) than the identified contemporary activity (MY 28 to 34). However, we assume that large

218 variations of surface temperatures within the observation time of our investigations and in the

219 study region did not occur and that annually temperatures did not show any large variations. TES

220 data were processed and downloaded directly from the TES webpage at the Arizona State

221 University (ASU) (http://tes.asu.edu/data_tool/). 


\subsection{Methods}

\subsubsection{Mapping of gullies and slopes}

We have mapped all gullies within the study region based on CTX images in order to place our detailed observations in context and assess the representativeness of the HiRISE sampling. In total, 17,760 single gullies were identified and marked. Individual gullies were identified by clearly visible alcoves associated with depositional fans, which are the most prominent features of a gully. Channels are more difficult to identify because sometimes their widths are below the resolution of the CTX data used. Hence, some of the identified sites may be relict gullies, lacking channels. We also identified and marked all gullies that were present within the multi-temporal HiRISE imagery $(n=2,067)$.

\subsubsection{Multi-temporal analysis}

For the identification of areas with both gully activity and high spatial and temporal repeat coverage of high-resolution images, we used the Multi-Temporal Database of Planetary Image Data (MUTED; Heyer et al., 2018). The web-based tool enables users to identify orbital images covering the same surface area on Mars based on user-defined spatial and temporal constraints. In particular, the database was used to find multi-temporal images with a spatial resolution better than $15 \mathrm{~m} /$ pix (for CTX images) within the area of interest.

After the import of multi-temporal HiRISE imagery into an ArcGIS project, we manually georeferenced particular images to get the best visual overlap to identify changes between the images. In a first step, we focused in the comparison of images with similar timings within a year (comparable solar longitudes) and similar solar incidence angles. This was done so as to have comparable shadows on the surface, which makes it easier to identify changes associated with 
246 activity and reduces mistakes, e.g., misidentification of shadows at different angles as mass

247 wasting activity. In a second step, we tried to narrow down the timing of activity to a minimum by

248 analyzing images within a year. If these images are available, (sometimes only a few images within

249 several different years are available), we identified the image "before" and "after" the activity

250 happened, which gives us the maximum timing within a year. For this study, we used the layer-

251 based ArcGIS structure to click manually through all available HiRISE images (Figs. 3-7).

252

\subsubsection{Slope measurements and topography}

254 Slope measurements of six active gullies based on HiRISE-Digital Terrain Models (HiRISE-

255 DTMs) were conducted (in red, Figure 8). We used one publicly released HiRISE-DTM (HiRISE

256 stereo pair ESP_013097_1115 and ESP_013585_1115) in region 5 (Figure 8b) which was

257 downloaded from the UA-HiRISE webpage (https://www.uahirise.org/dtm/) and we processed

258 another HiRISE stereo pair, ESP_023290_1090 and ESP_048608_1090, in region 11 (Figure 8a)

259 with the standard routines in the USGS Integrated Software for Imagers and Spectrometers (ISIS3)

260 and SOCET SET (Kirk et al., 2008). Both DTMs were used to visualize the slope angles of the six

261 active gullies (Figure 8: A, B, F, G, L, N) in comparison with non-active adjacent gullies (Figure

262 8: C, D, E, H, I, J, K, M, O, P). Profile measurements followed the path from the beginning of their

263 alcoves, through their channels, and across their aprons to the termini of the slopes (Figure 8).

264 Vertical exaggeration is about 2.7 in the displayed figures. For a better statistical analysis of all

265 gullies, we calculated the average slope angle of each individual gully separated in segments of $266100 \mathrm{~m}$ (Figure 8 and Supplementary Table 02). With this method, we were able to identify broad

267 trends in the slopes of the gully profiles. 


\subsubsection{Orientations}

270 We have undertaken four different measurements of orientations, binned into $10^{\circ}$ azimuth

271 intervals: (1) the number of pixels of all gullied slopes identified on CTX imagery $(\mathrm{n}=8,303)$

272 based on an aspect map derived from a 21-pixel moving window applied to the MOLA polar 273 gridded data at $460 \mathrm{~m} / \mathrm{pix},(2)$ all individual gullies $(\mathrm{n}=17,760)$ found on CTX imagery, (3) the

274 number of pixels of all gullied slopes identified on HiRISE imagery $(n=1,430)$ also based on the 275 same aspect map used for gullied slopes identified on CTX imagery, and (4) all active gullies $(\mathrm{n}=$ 276 35) based on multi-temporal HiRISE imagery (Figure 9). Individual gully orientation 277 measurements were derived from the mapped gully alcoves (as points) and sampling the value 278 directly underneath the point representing the alcoves of the underlying MOLA aspect map. 279 Orientations of active gullies were derived from the long profiles of the gullies they were hosted 280 in and, if possible, from the direct visible path of active dark flow-like feature. The analysis of the 281 gullied and non-gullied slopes was carried out on all pixels with slopes $>6^{\circ}$ because this value 282 was the lowest value that reliably captured all the gullied and non-gullied slopes without including 283 parts of the plateaux or pit-floors. Please note that the resolution of the MOLA aspect map 284 smoothed out the gully-alcoves so that it represents the general orientation of the hillslope.

285 The number of pixels of all gullied slopes (1) and (3) were divided by the orientation of all pixels 286 of all slopes (gullied and non-gullied CTX-identified slopes: 43,632 pixels in total; gullied and 287 non-gullied HiRISE-identified slopes: 1,648 pixels in total) to account for the influence and biases 288 of the general pre-existing topography, resulting in normalized data. Densities for all gullies (2) 289 and active gullies (4) were calculated by (2) dividing the number of all gullies by the total area with gullies based on CTX imagery (in pixels) for each orientation, and (4) dividing the number 
291 of all active gullies by the total area with gullies based on multi-temporal HiRISE imagery (in 292 pixels) for each orientation, respectively.

\subsubsection{Slow small-scale displacement detection}

295 To investigate the possibility of small-scale movements like creep as precursors to gully activity, 296 which can only be observed over multi-annual time scales, we applied a method called digital 297 image correlation (DIC). We produced four HiRISE-DTMs of region 11 to investigate the flow 298 event that occurred between MY32 and 33 (Figure 4) as well as to study general gully activity in 299 the region. We used five HiRISE-images: PSP_005621_1090, ESP_023290_1090, 300 ESP_030859_1090, ESP_039747_1090 and ESP_048608_1090 to cover the time between MY 28

301 and 33. DTM production was conducted using the Ames Stereo Pipeline (ASP, Beyer et al., 2018).

302 Governed by the available HiRISE images, all produced DTMs are either pre-event or co-event 303 DTMs, i.e., no post-event DTM could be produced. The change in surface appearance and texture 304 due to the recent flow feature that occurred between MY 32 and 33 is minimal and did not influence 305 the quality of the image matching during stereo correlation. All images were bundle adjusted and 306 matching was performed with a Bayes EM-weighted affine adaptive window correlator to ensure 307 the highest possible DTM quality. Due to the good correlation quality, the point cloud files could 308 be meshed to DTMs with very high spatial resolutions ranging from 0.5 to $3 \mathrm{~m} / \mathrm{pixel}$. Despite the 309 low noise content, all DTMs feature distinct striped inter-CCD seam artifacts that are common for 310 HiRISE-based DTMs. Tab. 2 in the Appendix reports additional relevant details about the 311 produced and used DTMs.

312 Orthorectification was performed using the Ames Stereo Pipeline, where DTMs from timeframes 313 MY 28 to 30 and MY 28 to 33 have been used to orthorectify HiRISE images PSP_005621_1090, 
314 ESP_023290_1090, and ESP_048608_1090 (Figure 10). This was necessary because digital image correlation (DIC) needs highly accurate orthorectification to extract small-scale horizontal surface 316 displacements.

317 DIC is an image processing technique that allows for the quantification of coherent, in-CVP 318 (camera viewing plane) surface displacements in multi-temporal imagery (Ayoub et al., 2009; 319 Heid and Kääb, 2012; Bickel et al., 2018). The technique is limited by its ability to co-register 320 pixel neighborhoods within a specified search window, i.e., incoherent or too large surface 321 displacements between two image acquisitions will cause a loss of signal. This usually limits the 322 applicability of DIC to monitoring of continuous and slow displacements, e.g., of glaciers (Heid 323 and Kääb, 2012), volcanic edifices (Casu et al., 2011), and slow moving landslides (Bickel et al., 324 2018). This limitation is particularly restrictive for space- and airborne sensors, as revisit rates are 325 usually lower and the displacement of objects between two acquisitions might be larger, and 326 potentially, too large. On Mars, DIC has successfully been applied to monitor dune migration and 327 sand fluxes using HiRISE imagery, e.g., in Nili Patera (Bridges et al., 2012) although it was 328 unsuccessful for coseismic displacement of faults in Cerberus Fossae on Mars (Grindrod et al., 329 2018).

330 The three above mentioned orthorectified HiRISE images have been selected for the DIC analysis 331 for two reasons: 1) Their maximum temporal baseline, as a larger difference in time will allow for 332 the detection of smaller displacements (PSP_005621_1090 of MY 28 and ESP_048608_1090 of 333 MY 33); and 2) As they could potentially indicate pre-event displacement in the gully of interest 334 (PSP_005621_1090 of MY 28 and ESP_023290_1090 of MY 30). Prior to DIC ingestion, a 335 dynamic contrast enhancement has been applied (Wallis filter) and all orthorectified images were 336 co-registered with sub-pixel accuracy, as past studies have found that these steps generally increase 
337 the correlation quality and coverage of the displacement field, if present (Bickel et al., 2018).

338 Subsequently, a frequency domain-based DIC code that is applying a Fast-Fourier-Transform

339 (Bickel et al., 2018) has been used to analyze the potential displacement between both image pairs, 340 using varying template and search window sizes. No post-processing of the results has been 341 performed to maintain the full interpretability of the results.

342

343

344 345 346

347

348

350

351

352

353

354

355

356

357

\subsubsection{Thermal investigations and seasonal frost coverage}

For thermal investigations, we collected all TES surface temperature datasets from MY 24 to 26 (except some measurements in MY 25 due to the influence of a global dust storm, see above) and binned them into five groups of $2^{\circ}$ of latitude from $66^{\circ}$ to $76^{\circ}$. We then calculated the mean of all individual measurements at the same time with their associated standard deviation (black lines of red dots in Figure 11). For our thermal studies, we investigated all available surface temperature datasets of all years together (except some data from MY 25 due to a global dust storm). No further division into different MYs was done because annually variations of MY 24 and 26 are small and negligible.

Furthermore, we also detected and investigated the seasonal frost coverage based on CTX and HRSC imagery. We identified seasonal frost coverage by its bright appearance compared to unfrosted regions (well-defined during the sublimation phases in spring by dark defrosting spots) and the assumption, that the study region is covered by surface frost during the winter, which was shown by Raack et al. (2015) in the same study region and substantiated by the general low surface temperatures during winter (Piqueux et al., 2003). For investigations of the timings of surface frost, we looked into all available CTX and HRSC images of the study region. We generalized the frost cover and marked an image as "frosted" even when only a small part of the image shows bright 
360 ice cover. This results in detailed information on the timing of surface frost in the complete study

361 region based on two different datasets without detailed analyses of local differences of frost 362 coverage such as orientations and altitude.

\section{Results}

365 We have identified 25 regions with multi-temporal HiRISE coverage (see black rectangles in 366 Figure 2), 13 regions include coverage of gullies. In total, 2,067 individual gullies were identified 367 on multi-temporal HiRISE images. In seven regions we identified contemporary active mass 368 wasting features within gullies. Overall, we found only $35(\sim 1.7 \%)$ individual gullies that showed 369 activity within MY 28 to 34 (yellow dots in Figure 2 and Supplementary Table 01). One large 370 gully showed two independent activities at two different places in the wide alcove, therefore we 371 classified these activities as gully independent activities 32 and 33 (see Supplementary Table 01). 372 The activity can be divided into flow-like features $(\mathrm{n}=22)$, as well as block movements within 373 gullies $(\mathrm{n}=16)$, where three of them are combined features which makes 35 active gullies in total. 374 For seasonal investigations, multi-temporal coverage of some images within one martian year are 375 necessary. Due to the greater frequency of HiRISE-coverage of some regions within the study 376 area, we were able to narrow-down the activity of 10 gullies during one martian year.

\subsection{Present-day mass wasting activity on multi-temporal HiRISE imagery}

379 Present-day activity was defined by clearly visible erosion and/or deposition of material down a 380 gully. Although some gullies could also show seasonally generated albedo differences and dark 381 flow-like features, no sediment transport was detectable in these gullies so we classify these gullies 
382 as "non-active". We distinguished between flow-like features (dark toned flow-like forms with

383 visible transport of material) and block movements (movement of blocks down the gully slope).

\subsubsection{Flow-like features}

386

387

388

389

390

391

392

393

394

395

396

397

398

399

400

401

402

403

404

The most widespread present-day activity of gullies are flow-like features. We found 22 gullies with active flow-like features or new deposits and erosion forms most likely caused by flow-like activity. Three of them are associated with identifiable block movements. Ten of these 22 active gullies show flow-like activity within only one MY and six of these ten gullies show repeated activity. In detail, three gullies show activity in two separate MYs, two gullies within three different MYs, and one gully shows activity within five MYs (see Supplementary Table 01). Movements within repeatedly active gullies originated in the same places and covered the same depositional areas of the gully.

Flow-like features have identifiable transport of sediment, which is probably dust and/or sand (Raack et al., 2015). The presence of pervasive surface sand/dust is supported by the presence of pervasive surface ripples and the seasonal appearance of dark spots on gully aprons, and next to or within gully channels. These dark spots are likely formed by transport of sand and dust from under the translucent slab ice (e.g., Piqueux et al., 2003; Kieffer et al., 2006; Thomas et al. 2011) as larger particles cannot be mobilized (see further discussion of these features in Section 4.1).

Based on our seasonal observations, we found that the flow-like features occurred episodically, i.e., changes appeared between two images and were not gradual. This was observed as an accumulation of gully channel material in the "before" image, whereas the "after" image displayed distinct flow features over the apron (Figure 3). Sometimes, the deposited material was observed without observable accumulation of material in the channel beforehand. The flow-like features 
appear dark compared to their surroundings. Over time, the transported material brightens and fades until mid-summer, which could be due to gradual deposition of dust, comparable to the

407 fading of, e.g., dust devil tracks (Reiss et al., 2016) and slope streaks (Schorghofer et al., 408 2007).However, fading of a flow-like feature in Sisyphi Cavi was also observed by Raack et al.

409 (2015) and their investigation of the corrected Lambert albedo images showed that the flow-like 410 feature did not brighten, but that the surroundings darkened over time due to seasonal frost 411 sublimation. In summer, the surroundings and the flow-like features have a very similar albedo 412 which can only be observed in the corrected albedo images. This indicates that the brightening is 413 not caused by dust deposition but is a result of frost sublimation. The brightening did not appear 414 to alter the changes in surface relief associated with the dark flow-like features, therefore this study 415 will focus on the formation of these mass movements and not their fading.

416 In some cases, seasonal observations were not possible and no dark flow-like features were 417 identifiable, but a change of the surface relief caused by sediment transport was still visible. In 418 Figure 4 an example flow-like feature is shown, with the formation of relatively small new 419 transportation channels (Figure 4b), block movement (Figure 4b), erosion of ripples or 420 superposition of ripples with transported material (Figure 4c), and a general change of the relief of 421 the surface. Thickness and consequently volume calculations cannot be made because it was not 422 possible to measure the height of the newly formed deposits, either on digital terrain models 423 (DTMs) or with shadow measurements (for some volume estimations, see Raack et al., 2015). This 424 indicates that the deposits have a thickness of some decimeters or less.

425 One gully (\#3) in the study region had clearly identifiable headwall erosion and loss of material, 426 which was transported down the gully. This was the only gully where the source region of 427 transported material was clearly visible and measurable (Figure 5). Raack et al. (2015) analyzed 
the same gully but no source region for the identified activity was found as it only became apparent

429 in more recently acquired images. At some localities, the gully-alcove headwall erosion of up to

430 several meters (max. 5 m) occurred between MY 29 and MY 33. This headwall erosion is the

431 first and only evidence of a clearly identifiable source region for transported material in the study

432 region.

433 The only noticeable features located upslope of observed sediment transport are small (up to 15

$434 \mathrm{~m}$ ), dark flow-like features on the steep flanks of the gully channels (Figure 6). These features

435 were found in some active gullies, as well as in non-active gullies. We infer that sediment erosion

436 and transportation are taking place at these locations, because there dark layers paralleling the crest

437 of the gully channel flanks (Figure 6 d-e), from which the small dark flow-like features emanate.

438 A second indicator for sediment transport, even if it is not topographically visible, is the 439 accumulation of dark material within gully channels (Figure 6). These accumulations are formed

440 by confluence of the small, dark flow-like features. This was also proposed, but not directly

441 observed by Raack et al. (2015), due to the lack of datasets with sufficiently high resolution.
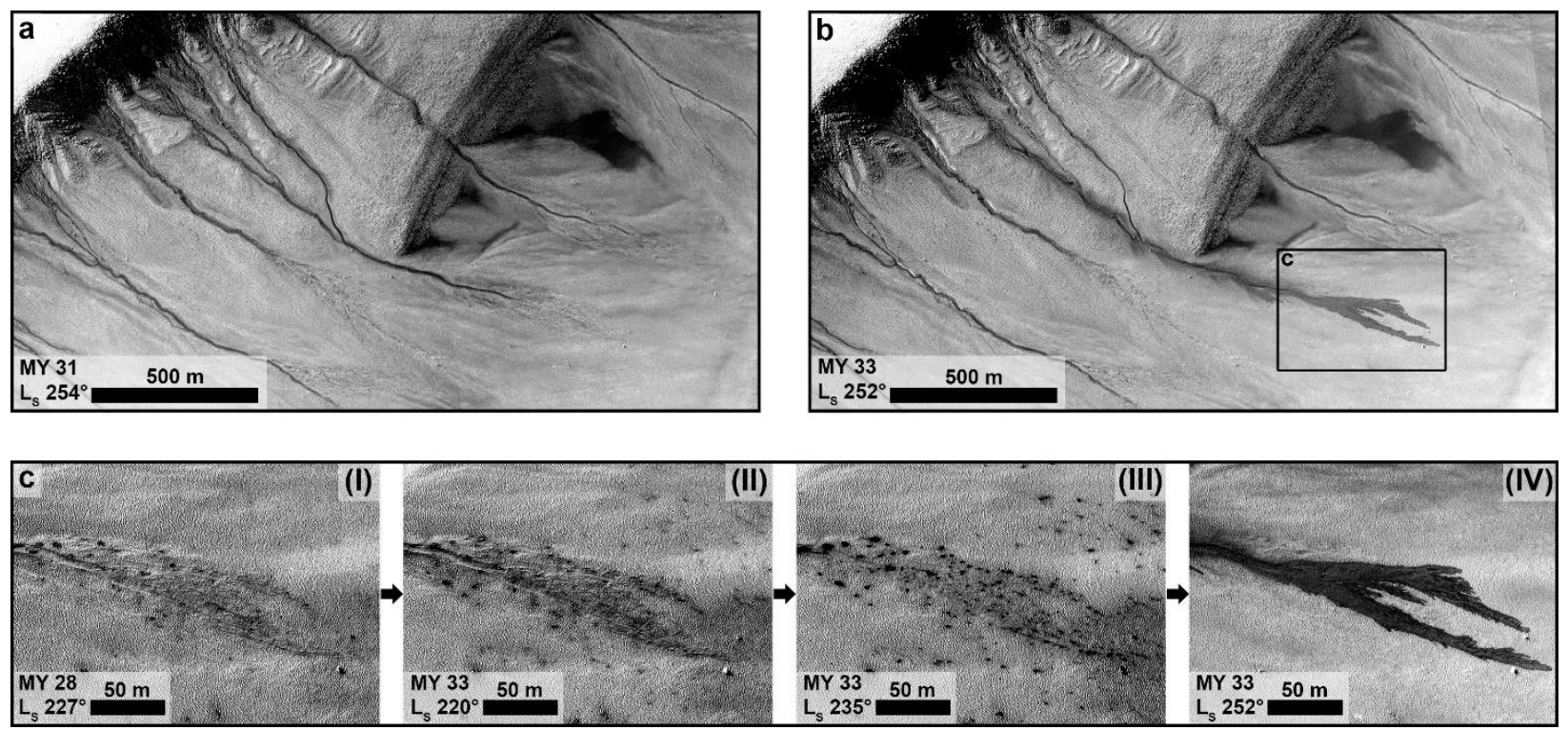
443 Figure 3: Before and after images of a south-east facing slope of a polar pit (Region 5, see Figure 444 1) within MYs 31 and 33 at comparable Ls of $254^{\circ}$ (a) and $252^{\circ}$ (b). The downslope direction is 445 from top left to bottom right. The active part of the gully in the middle of the images (gully \#1, 446 same as gully $\mathrm{N}$ in Figure $8 \mathrm{~b}$ ) is apparent because of the appearance of a dark flow-like feature in 447 MY 33, which superposes the existing apron and has deposited new material. (c) I-IV Detailed 448 views of the evolution of the appearance of the active part of the apron in MY 28 (Ls $227^{\circ}$ ) and 449 MY 33 at Ls $220^{\circ}, 235^{\circ}$, and $252^{\circ}$. Between the first (I, MY 28) and the second image (II, MY 33 450 at Ls $220^{\circ}$ ), there is no identifiable change of the surface, except for in the pattern of the annually 451 active dark defrosting spots. Between the second (II) and the third (III) image, these dark defrosting 452 spots expand, but no flow is visible. 26 sols later in the fourth (IV) image, a dark flow is visible 453 and the dark defrosting spots are no longer visible, which indicates advanced sublimation of the 454 slab ice and probably the complete defrosting of the surface. HiRISE-images (a) 455 ESP_030503_1115, (b) ESP_048107_1115, (c) (I) PSP_003511_1115, (II) ESP_047039_1115, 456 (III) ESP_047751_1115, (IV) ESP_048107_1115. North is up in all images. 

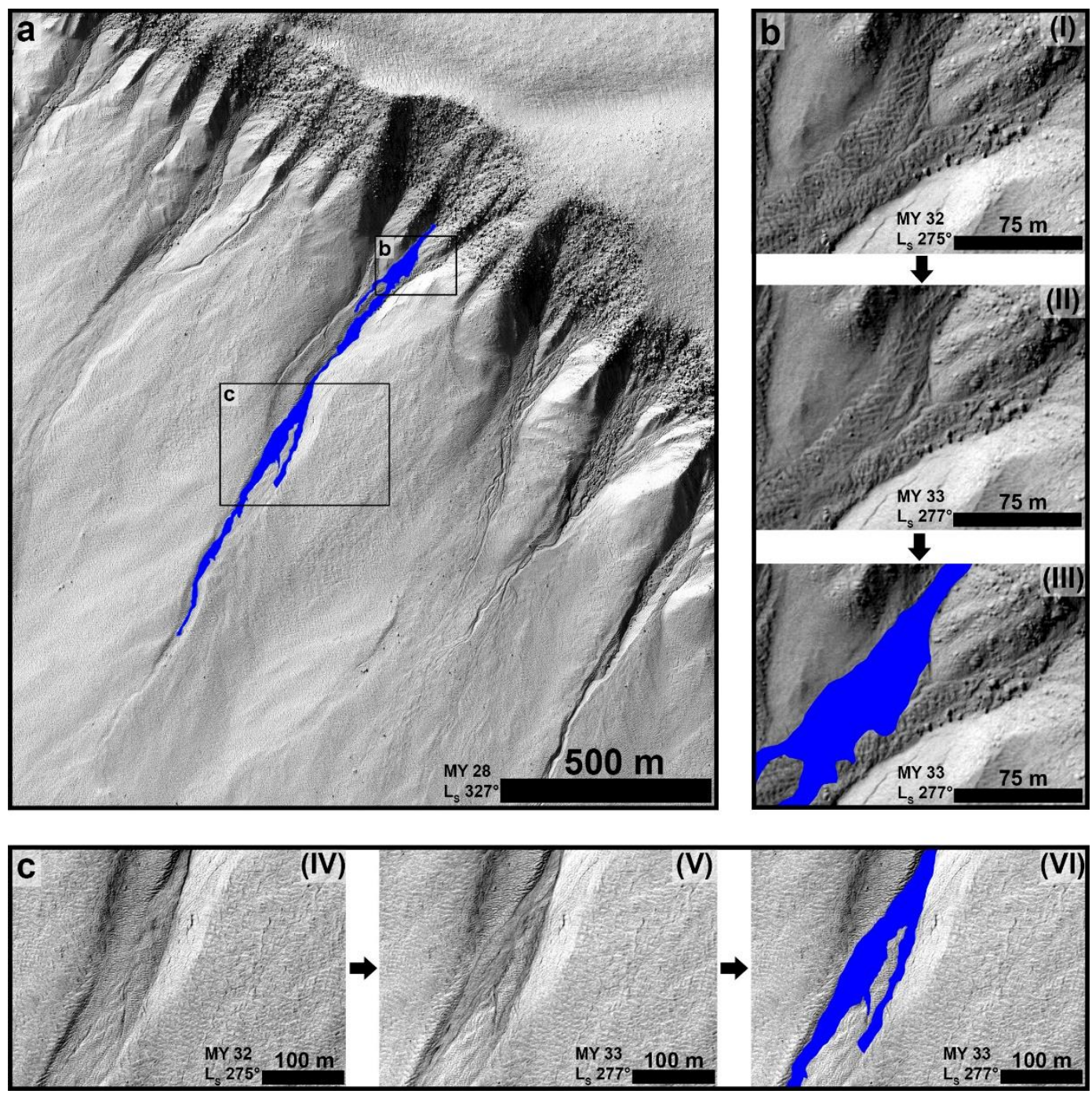

458 Figure 4: (a) Present-day active gully \#11 (MY 28, Ls 327º) on a south-west facing slope in

459 Region 11 (see Figure 1 and gully A of Figure 8a). The area within the gully affected by the activity

460 (erosion and deposition of material) is mapped in blue. With more than $1 \mathrm{~km}$ in length, this active 461 mass wasting form was the largest identified in this study. (b) (I-III) Close-ups of a part of the 462 gully alcove before (I), in MY 32 at Ls $275^{\circ}$, and after (II), in MY 33 at Ls $277^{\circ}$, almost exactly 463 one martian year apart. The third image (III) shows the affected region (mostly by erosion) mapped 464 in blue. (c) (IV-VI) Close-ups of a part of the gully's transportation channel before (IV), in MY 32 465 at $\mathrm{Ls} 275^{\circ}$, and after (V), in MY 33 at Ls $277^{\circ}$, comparable to (b) in terms of timing. Similarly, the 466 third image (VI) shows (mapped in blue) the region affected by activity, by erosion, as well as 
deposition. HiRISE-images (a) PSP_005621_1090, (b) (I) ESP_039747_1090, (II and III) images.
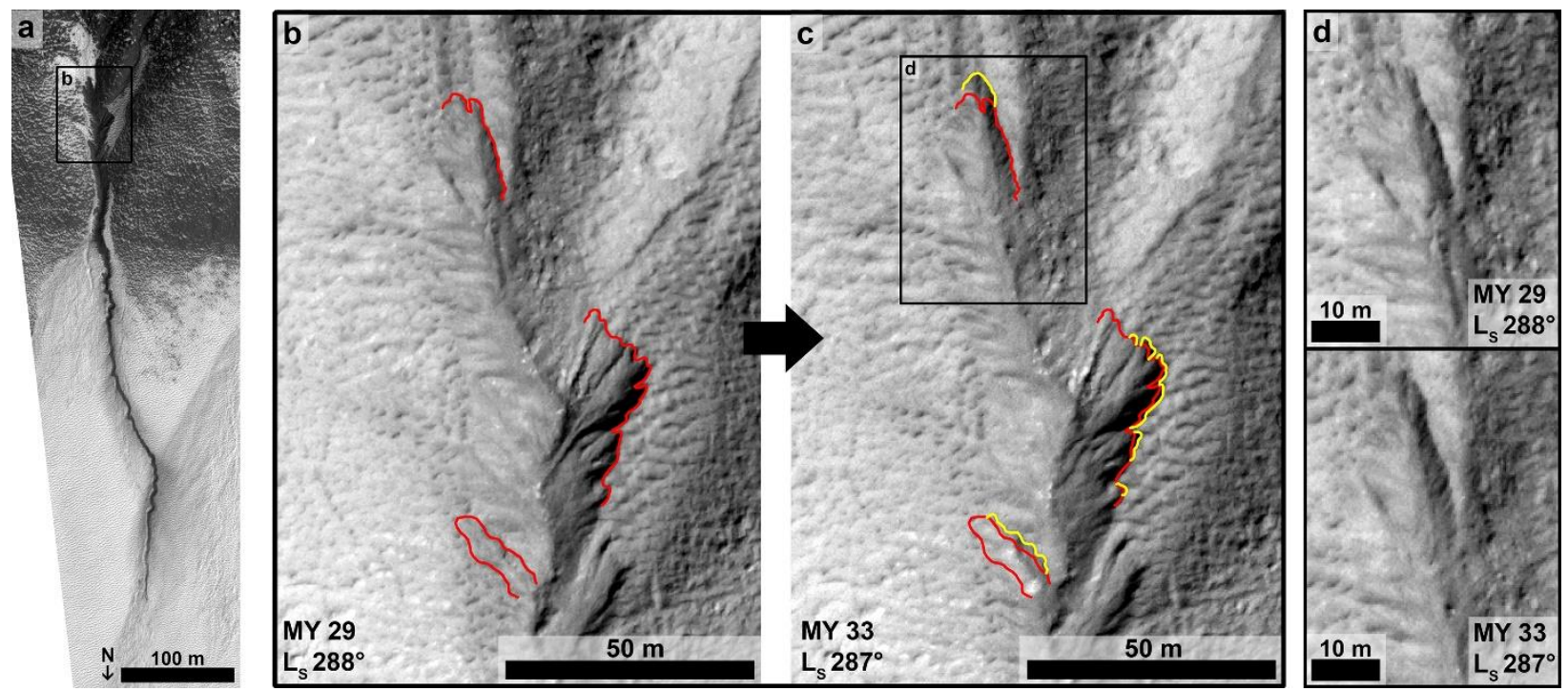

471 Figure 5: Headwall erosion of active gully \#3 presented in Raack et al. (2015) (also seen in Figure

$4728 b-$ gully $G) .($ a) Overview of the active gully. The gully shows activity every year in the form of

473 a large, dark flow within the gully channel and new material superposition on top of the gully

474 apron (Raack et al., 2015). (b) Detail of the gully alcove in MY 29 at the beginning of summer (Ls

$475288^{\circ}$ ). The large gully alcove was filled with material (rippled surface, presumably ice-rich mantle,

476

e.g., Mustard et al., 2001; Raack et al., 2012), which is eroded, leading to a smaller gully alcove.

477 Red lines represent clearly identifiable outlines of the headwall of the alcove. (c) In MY 33 at the

478 beginning of summer ( $\operatorname{Ls} 287^{\circ}$ ) headwall erosion of a few meters could be identified (yellow lines

479 represent the new headwall of the alcove). Especially the uppermost region of the gully alcove

480 shows the highest erosion rate within the four martian years. (d) Detail of the top of the gully

481 alcove in MY 29 and 33. Erosion of a few meters of material is clearly visible. HiRISE-images (a)

ESP_029725_1115, (b) ESP_013585_1115, and (c) ESP_048819_1115. North is down in all images as indicated. 

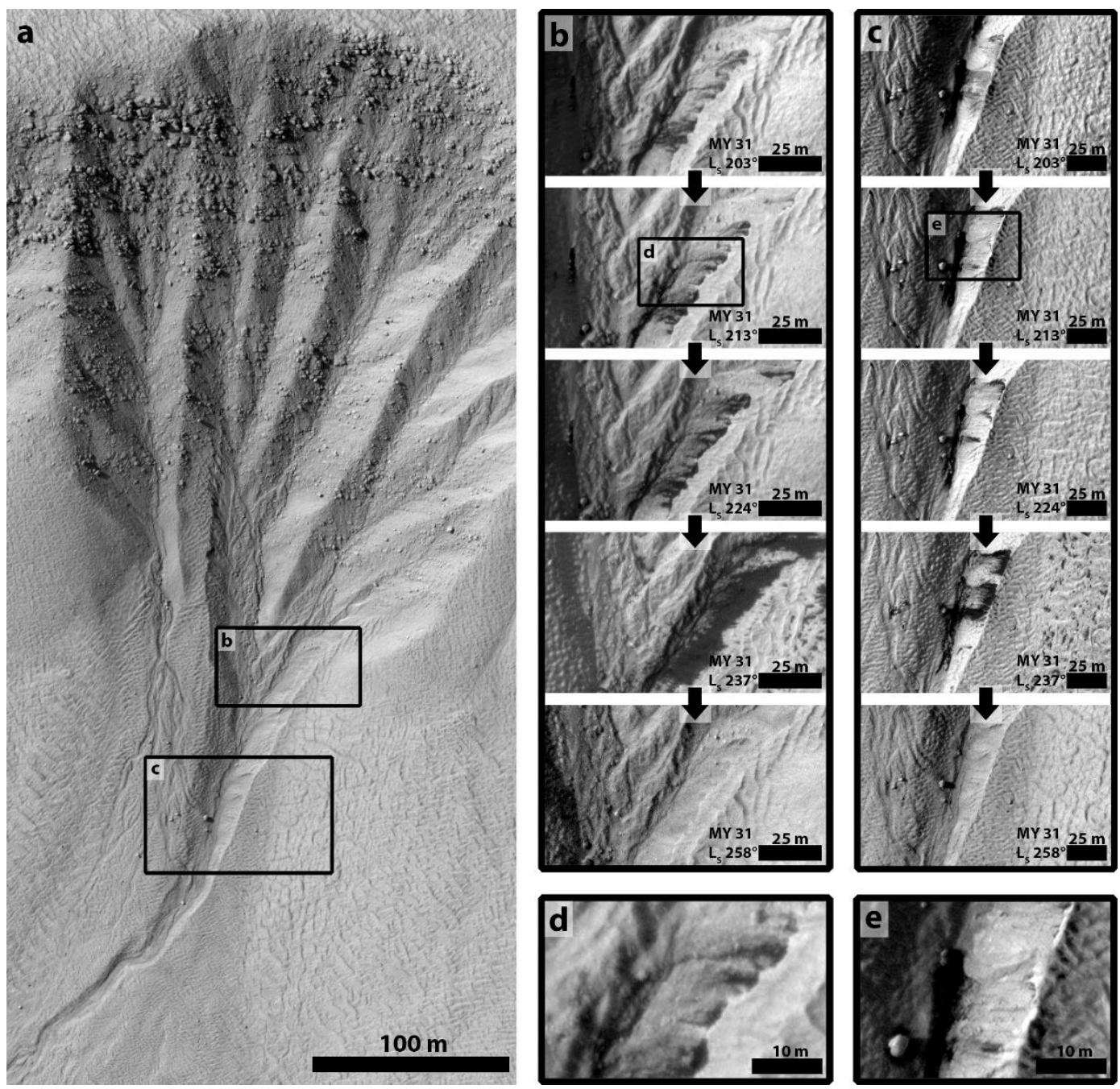

Figure 6: (a) Example of a gully alcove with identifiable small, dark flow-like features emanating

486 from a layer on gully channel flanks. Here, the small, dark flow-like features are too small to show

487 any transported sediment. The small, flow-like features accumulate within the gully channel, but

488 there is no associated large flow-like feature with transported material. (b) + (c) Two detailed

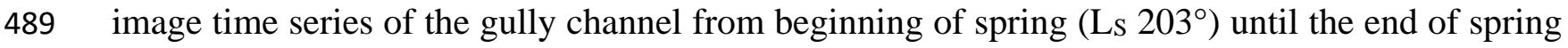

$490\left(\operatorname{Ls} 258^{\circ}\right)$ where defrosting is at its maximum. Dark material flows down the gully channel flank

491 into the interior of the channel. Here, dark material accumulates and flows down the gully channel,

492 which is detectable in (c). (d) + (e) Details of the layer on the gully channel flanks from where the

493 dark material emanates. The layer is only several meters wide and identification with HiRISE 
494 images is difficult. (a) Overview: HiRISE-image ESP_040486_1105 (Ls 309). (b) + (c)

495 Sequence: HiRISE-images ESP_029475_1105, ESP_029686_1105, ESP_029897_1105, 496 ESP_030174_1105, and ESP_030609_1105. North is up in all images.

497

498

499

500

501

502

503

504

505

506

507

508

509

510

511

512

513

514

515

\subsubsection{Activity of block movements}

Block movements are clearly identified transported blocks of about 1-2 $\mathrm{m}$ in diameter between images which could have slid, tumbled or rolled down slope under gravity or have been transported in a flow. In the study region, block movements only occur within gully alcoves where slopes are relatively steep and have undergone more recent modification compared to non-gullied slopes. Furthermore, gully alcoves uncover an underlying rocky surface, which is otherwise superposed by a mantling deposit in this region (Figure 7). This rocky surface is often the source for blocks, which then move down the slope.

We observed 16 different gullies (three of them also associated with identified dark flow-like features) with identifiable block movements within the study region. Only one block movement could be seasonally investigated (Figure 12), while all other block movements occur in regions with only limited temporal HiRISE-coverage. The number of 16 block movements is a minimum number because block movements are hard to identify and some block movements (particularly short displacements) are likely to have been missed during our investigations. Three of the identified gullies show a combined activity of flow-like features and block movements. Here, blocks moved several meters in the same direction as the flow-like features and/or were superposed by transported material. In the last case it is hard to distinguish between moved blocks or just superposed blocks by loose fine material. Tracks associated with the block movements were not 
516 found. Only in one case (Figure 7), the path of the block down the slope is roughly traceable by

517 the displacement of some other blocks.

518 The distance moved by the blocks varied between $\sim 1 \mathrm{~m}$ to $230 \mathrm{~m}$ at maximum (Figure $7 \mathrm{~b}$ ). Most

519 blocks moved only 1-2 meters $(n=9)$, which typically corresponds to a block rolling from one

520 face to another. The other remaining block movements $(n=6)$ moved between 5 and 40 meters.

521 In one case, a block seemed to disappear completely, which means it was not found in the 'after'-

522 image and therefore the travel distance could not be measured.
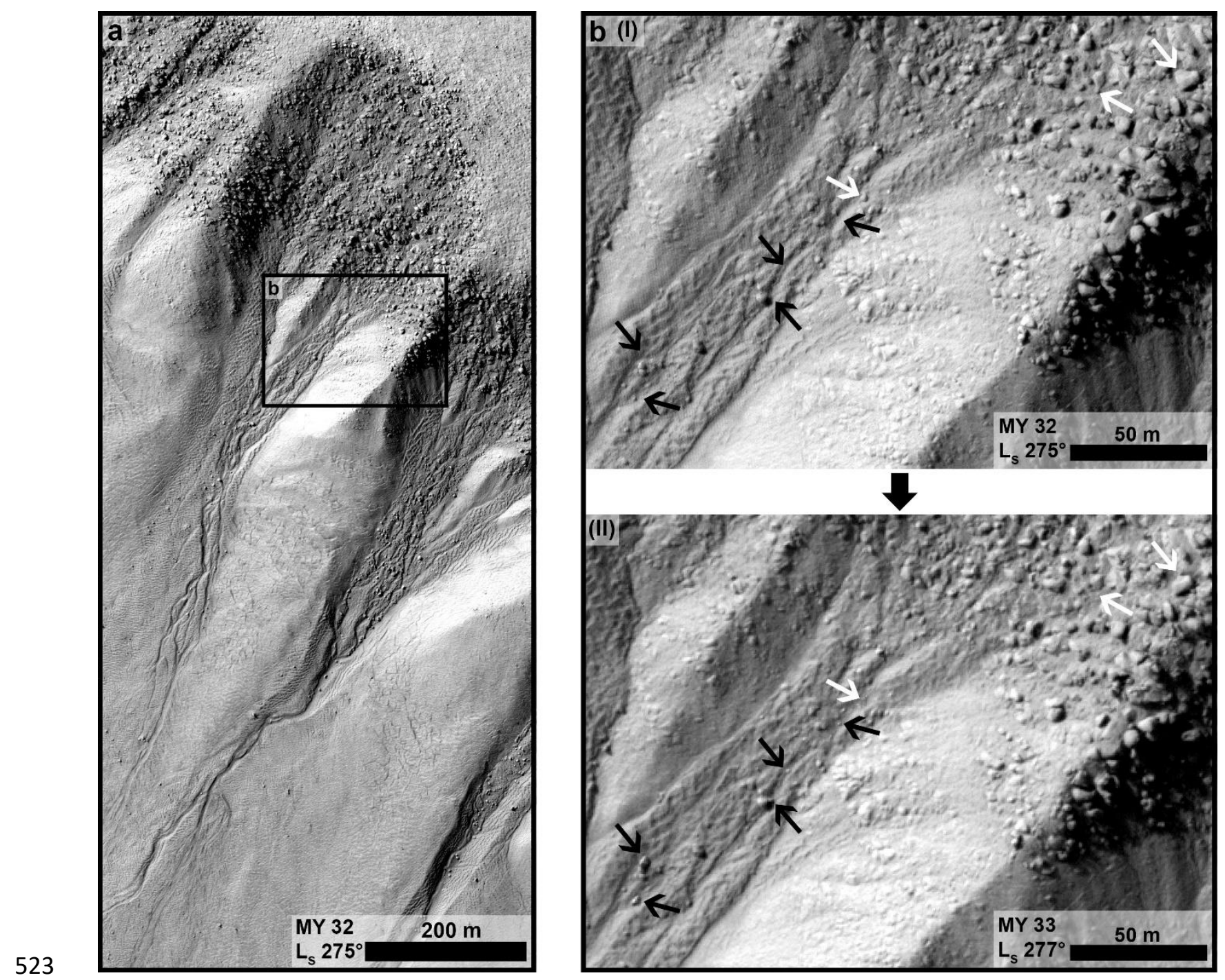
524 Figure 7: (a) Gully \#12 with present-day activity in form of block movement within the alcove in

525 Region 11 (see Figure 2) on a south-south-west facing slope. Overview image (a) and detail (b)

526 (I) were taken in MY 32 at Ls $275^{\circ}$. (b) Detail is presented as before (I) and after (II) images

527 whereupon the after (II) image was taken nearly exactly one martian year later (MY 33 at Ls $277^{\circ}$ )

528 than the before image. White arrows point to eroded/disappeared blocks, while the black arrows

529 point to newly deposited blocks. The transported blocks are generally only a few pixels in diameter

530 ( 1 m); only the largest block (lower left) has a diameter of about 4-5 m. HiRISE-images (a) and

531 (b) (I) ESP_039747_1090, (b) (II) ESP_048608_1090. North is up in all images.

532

533

534

535

536

537

538

539

540

541

542

543 position of the activity is bracketed by black bars with arrows.

544 In region 11, the shape of all the gullies (6 measured gullies, 3 with present-day activity) is very 545

\subsection{Topography, orientation, and digital image correlation}

To identify possible mechanisms responsible for the identified present-day activity of gullies in Sisyphi Cavi, we investigated the topography of the active gullies based on HiRISE DTMs, the orientation of all slopes and gullies in the study region, and possible small-scale surface changes / activities based on digital image correlation of HiRISE images.

\subsubsection{Topography}

We measured the topographic long profiles of selected gullies on slopes of region 11 (Figure 8a) and region 5 (Figure $8 \mathrm{~b}$ ) by tracing the path of the gullies from the top of the alcove to the end of the depositional fan. Gullies marked by red profiles in Figure 8 show present-day activity and the comparable (Figure 8a (1)), and no systematic differences in the general shape of the long profile between active and non-active gullies could be identified. All gullies have a rectilinear profile with 
547 a steeper upper part and shallower lower part, which starts around $400 \mathrm{~m}$ downslope, 548 corresponding to the change from exposed rocks to fans. Present-day activity originates at the 549 steeper upper part of the gullies and material is subsequently transported down the gully channel 550 to where slopes are shallower (around $10^{\circ}-15^{\circ}$ ).

551 Furthermore, the average slope angles calculated every 100 meters of gully length (Figure 8a (2)) 552 are broadly similar. The average slope angles in the alcove area reach maxima of between $30^{\circ}$ and $55345^{\circ}$ and diminish to around $20^{\circ}$ towards the base of the alcoves. The alcoves show a higher 554 variation in slopes compared to the rest of the profiles. The remaining downslope parts of the 555 profiles have relatively constant slopes of around $10^{\circ}$, which drop to $5^{\circ}$ in the last few hundred 556 meters. Two of the three active gullies (A and B) have steeper average slope angles in the first 200 557 to $300 \mathrm{~m}$, while other non-active gullies only show shallower slope angles. Gully slopes A and B 558 could be not measured in their entirety (the end of the profile is missing) because the DTM does 559 not cover the complete slope.

560 The profiles of the gullies in region 5 are very comparable to those in region 11 . However, they 561 appear a somewhat smoother and have shorter, steeper upper parts (around 200-250 m) than the 562 gullies in region 11 (Figure 8b (3)). Comparable to region 11, gully activity originates on the 563 steeper slopes at the beginning of the gully profile and continues down to shallower sloping 564 regions. Furthermore, the gullies in region 5 are also very comparable to each other, except gully 565 L, which appears smoother at the beginning than the others and has a steeper slope angle at the 566 end (similar to gullies $\mathrm{H}$ and $\mathrm{M}$ ). The smooth beginning is because the top of the profile is not 567 included in the DTM. The increase of average slope angles at the end is caused by the occurrence 568 of a ridge at the base of the slope (Figure $8 \mathrm{~b}(4))$. All other profiles show comparable patterns as 569 well as comparable average slope angles. Slope angles decrease from up to $\sim 50^{\circ}$ (alcove of gully 
$570 \mathrm{~N}$ ) down to $\sim 0^{\circ}$ (apron of gully L). Consequently, no differences of active and non-active gullies 571 in region 5 was found.

572 The average slope angles of all measured gullies of both regions are provided in Supplementary 573 Table 02. The average slope angles for the entire lengths of all measured gullies varied between $57416^{\circ}$ and $10^{\circ}$ (gullies A and B are not taken into account because the profiles do not extend to the 575 terminus of the hillslope and therefore have anomalously higher average slope angles). The 576 average slope angles of for the entire lengths of the active gullies ranges between $15^{\circ}$ and $10^{\circ}$, 577 which provides additional confirmation that no difference in topography between active and non578 active gullies is measurable. 

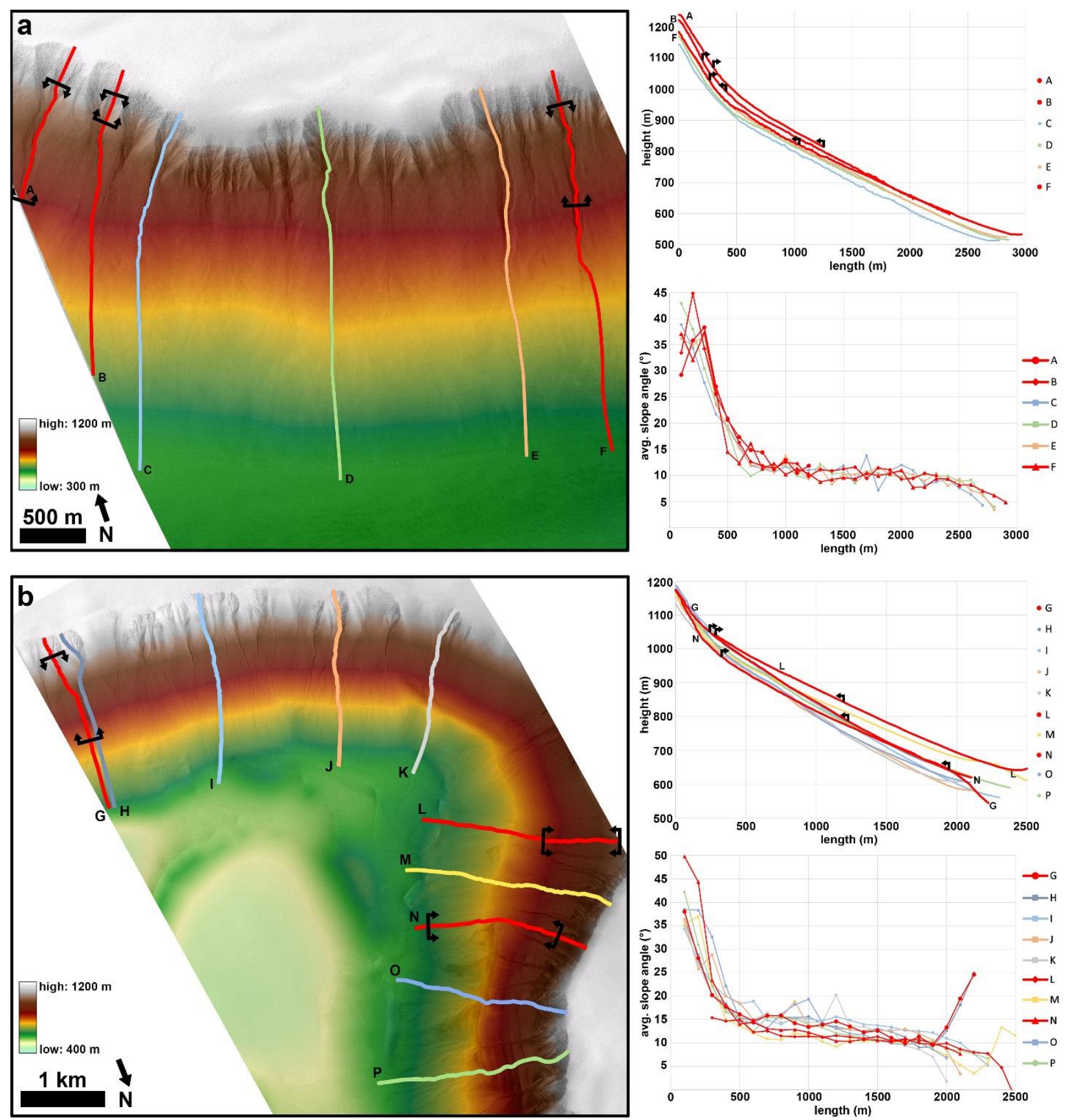

Figure 8: (a) Colorized DTM from HiRISE stereo pair ESP_023290_1090 and ESP_048608_1090 in region 11 (see Figure 2) with semi-transparent orthophoto. On the right side

582 are the associated topographic profiles as a function of height vs. distance from top of the alcove

583 (above) and as a function of average slope angles as calculated over $100 \mathrm{~m}$ segments (see also 584 table 1) vs. distance (below). The profiles start at the crest of the alcove and end at the visually 
585 identified terminus of the hillslope. Note that the termini of measured gullies (aprons) often stop

586 before the end of the slope. Active gullies (A, B, and F) are marked in red; between the areas of

587 the black bars with arrows, contemporary activity was identified. (b) Colorized DTM of HiRISE

588 stereo pairs ESP_013097_1115 and ESP_013585_1115 in region 5 (see Figure 2) with semi-

589 transparent orthophoto. See also Raack et al. (2015) for more information of this specific area. On

590 the right side same profiles as in (a). Active gullies (G, L, N) are also marked in red. Profiles G

591 and $\mathrm{H}$ have increasing slopes at the end of the profile due to the presence of a small local

592 depression. However, this has no influence on the gullies because the depression is located beyond

593 the end of the gully deposits.

594

595

\subsubsection{Orientation}

596 To identify a possible triggering mechanism of gully activity and to find differences between active 597 and non-active gullies, the orientations of gullies, gully densities, and gullied slopes based on CTX 598 and HiRISE imagery of the complete study region were investigated. Four different measurements 599 were performed:

600 (1) Orientation of pixels identified on MOLA gridded data ( $460 \mathrm{~m} / \mathrm{pix})$ of gullied slopes 601 (slope angle $>6^{\circ}$ ) found on CTX imagery. In total, 8,303 pixels cover all gullied slopes 602 603 and show a clear north-south trend (Figure 9a). After normalization against all slopes $>6^{\circ}$ in the complete study region (35,329 pixels), the north-south trend is still visible (Figure 9b), but not so distinct compared to non-normalized data. Both the normalized 605 and non-normalized orientation plots show a slightly preferred south-facing (or pole606 facing) trend for all gullied slopes. 
(2) Orientation of all gullies in the study region based on CTX imagery. In total, 17,760 individual gullies were identified and measured. The data show a strong north-south trend with slightly more south-facing gullies than north-facing gullies (Figure 9c). The density of gullies is remarkably uniform with orientation (Figure 9d). The highest peak of gully density is found between $50^{\circ}$ and $60^{\circ}$ (northeast) and a slightly lower density of gullies is found on south- to west-facing slopes.

(3) Orientation of pixels identified on MOLA gridded data $(460 \mathrm{~m} / \mathrm{pix})$ of gullied slopes (slope angle $>6^{\circ}$ ) found on multitemporal HiRISE imagery. In total, 1,430 pixels cover all gullied slopes (Figure 9e), while only 218 pixels cover non-gullied slopes. This is an effect of the intensive monitoring of gullied slopes with the HiRISE camera in this region. After normalization against all slopes $>6^{\circ}$ of multitemporal HiRISE-covered slopes (1,648 pixels), a very uniform distribution is visible (Figure 9f).

(4) Orientation of all active gullies based on multi-temporal HiRISE imagery. In total, 35 individual gullies show present-day activity and were measured. The data show a southwest and a northwest facing trend (Figure 9g). The color-coding represents dark flow-like features (in red) and block movements (black). Only two gullies are east facing. The density clearly shows a higher density of active gullies facing northwest (Figure 9h). Same color-coding as in Figure 9g), which shows the highest density of flow-like features orientated towards north-west. Comparison with Figure 9e reveals that the lack of active east-facing gullies could be due to imaging bias, but that the lack of north-facing active gullies is most likely real.

In summary, gullies tend to be oriented north-south in the study region with a slight bias towards south-facing slopes and the highest density towards the north. In contrast, active gullies tend to be 

facing active gullies.
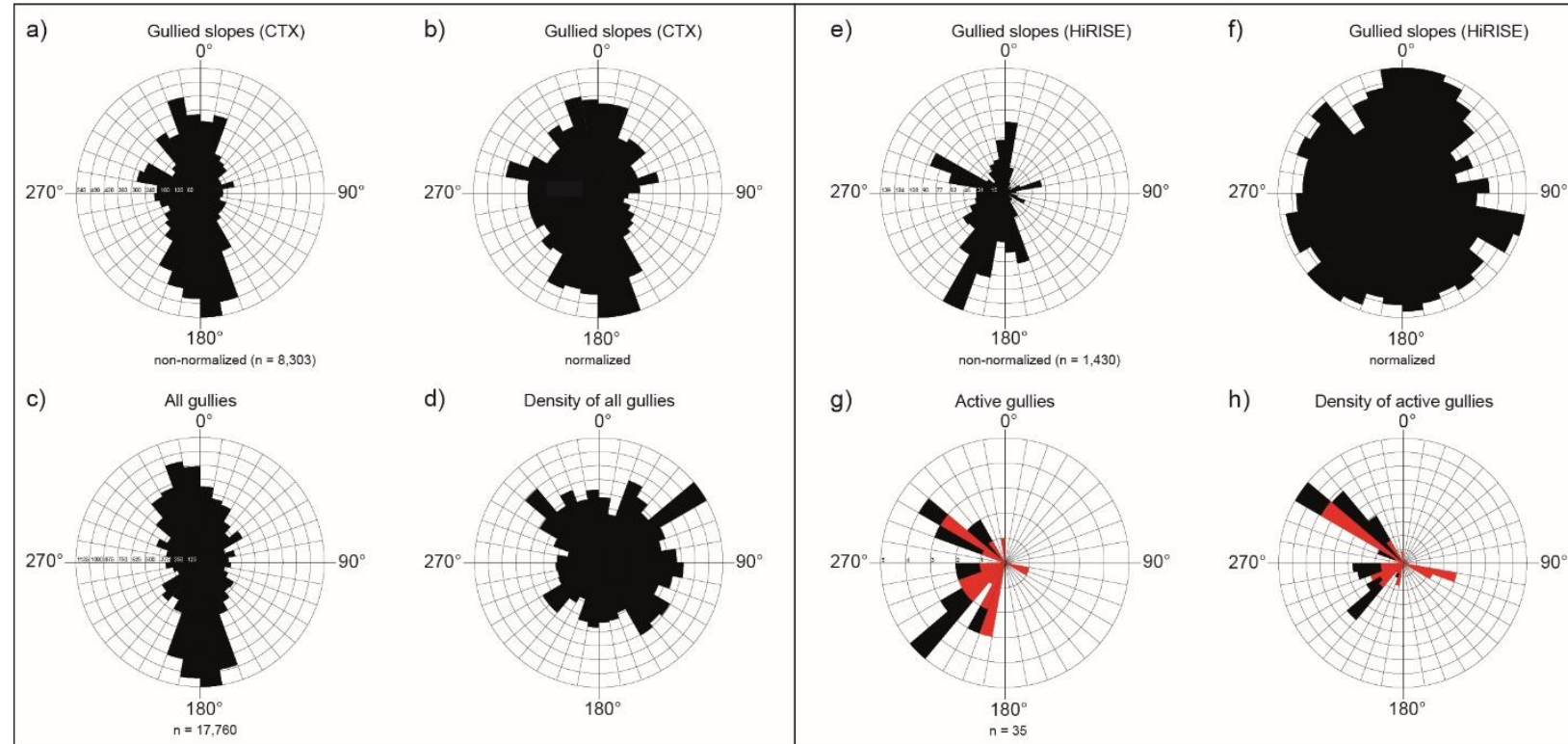

g)

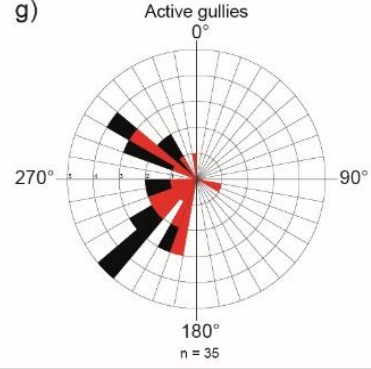

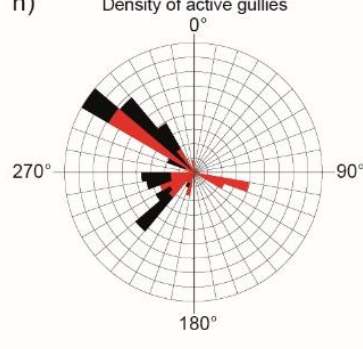

633

634

Figure 9: (a) Orientations of all sloping pixels with gullies based on MOLA data $(n=8,303)$ and (b) the same data normalized against all sloping pixels. (c) Orientations of all mapped individual gullies $(n=17,760)$ based on CTX imagery and $(\mathbf{d})$ densities of all mapped gullies measured in units of gullies per MOLA pixel (the data in c divided by a). (e) Orientations of all pixels with gullied slopes included in multi-temporal HiRISE imagery $(\mathrm{n}=1,430)$ and $(\mathbf{f})$ normalized by the total number of sloping pixels covered by multi-temporal HiRISE images. (g) Orientations of all investigated present-day active gullies $(n=35)$ identified in multi-temporal HiRISE imagery (red $=$ dark flow-like features and black $=$ block movements), and (h) densities of all active gullies measured in numbers of gullies per pixel (the data in g divided by f), same color-coding as in (g).

\subsubsection{Digital image correlation}

The correlation of both HiRISE pairs at location 11 that cover the event between MY32 and 33 (see also Figure 4) does not show any displacements in the periods from MY 28 to 30 (pre-event) 
646 and to 33 (co-event), respectively (Figure 10). This could indicate that 1) there is no pre-event

647 displacement of the hillslopes hosting the investigated martian flow-like features, and 2) that there

648 is no slope creep occurring at all or that such creep is smaller than $25 \mathrm{~cm}$ within the five observed

649 martian years, i.e., less than $\sim 5 \mathrm{~cm}$ per MY on average.

650 Parts of the displacement fields (Figure 10) show systematic and erroneous displacement values

651 that are the result of either 1) moving shadows that are caused by slightly different illumination

652 conditions for the used images or 2) inter-CCD seam artifacts. These types of artifacts cannot be

653 avoided, which is why the respective areas have been masked to maintain clarity (Figure 10). The

654 low root mean square error (RMSE) values, which are a measure for the quality of the image

655 correlation, across these affected regions of the images indicate that the rectangular patches in the

656 displacement fields are in fact caused by errors in the DTM used for the HiRISE image

657 orthorectification and are not actual (rapid) displacement.

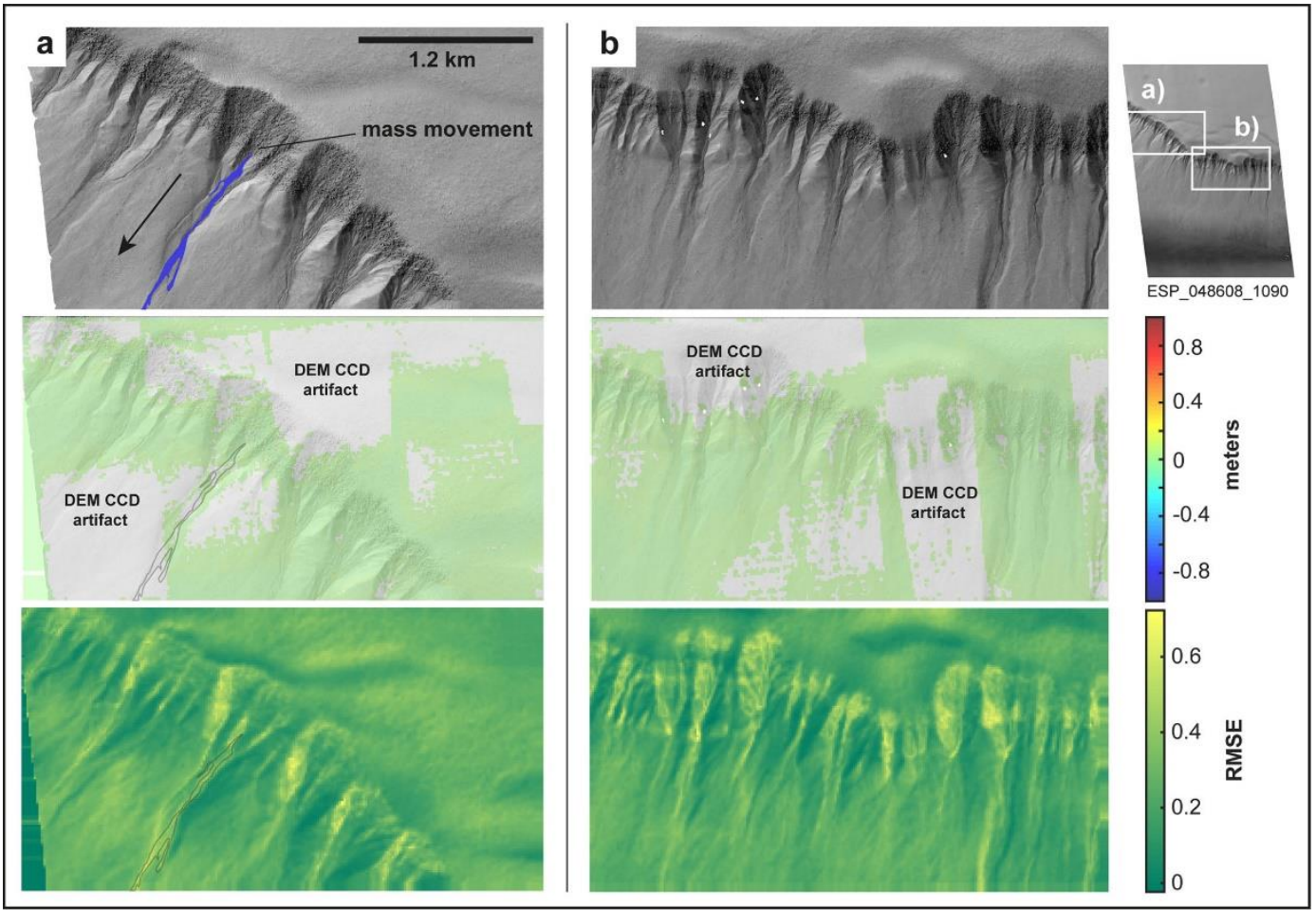


659 Figure 10: Displacement magnitude and associated correlation RMSE between HiRISE images 660 PSP_005621_1090 and ESP_048608_1090 (MY 28 to 33, i.e., the image pair with the maximum 661 temporal baseline) with focus on two different sites along the cliff of interest in region 11: a) the 662 portion where activity occurred in MY 33 at $\mathrm{Ls} 277^{\circ}$ (blue polygon, in the indicated direction) 663 (Figure 4), and b) a series of gullies further east. Images have been taken before (MY 28) and after 664 (MY 33) the activity of the gully. The accumulated displacement of the slope between MY 28 and 66533 appears to be less than one pixel $(\sim 25 \mathrm{~cm})$ or non-existent. Due to the occurrence of the flow 666 and due to systematic noise introduced by CCD artifacts, coverage of the region of interest is 667 incomplete. The correlation RMSE maps indicate areas in the images where matching accuracy 668 has been slightly reduced, particularly in the shadowed portions of the gullies (western gully 669 flanks). Overview based on HiRISE image ESP_048608_1090.

670 comparison to dark spots

673 Based on our large dataset of CTX, HRSC, and HiRISE images, we were able to correlate seasonal 674 frost coverage with the annual activity of gullies. Using TES data we could correlate these trends 675 with surface temperature. According to Raack et al. (2015), this seasonal frost cover is composed 676 mainly of $\mathrm{CO}_{2}$ ice with some minor contaminations of $\mathrm{H}_{2} \mathrm{O}$ ice and dust. Figure 11 shows the 677 seasonal trend in surface temperature with latitude combined with our observations of visible 678 surface frost. Each latitude band has a similar temperature trend with temperatures stable at around $679150 \mathrm{~K}$ until defrosting starts, the temperature then climbs relatively quickly and reaches a convex680 up plateau extending over the summer. For latitudes between 72 and $76^{\circ} \mathrm{S}$ there is a slight 681 precursor rise in surface temperature before the steep climb. The last image without surface frost 
682 does not occur until $\mathrm{L}_{s} \sim 30^{\circ}$ after the plateau is reached. For more equatorial latitudes the rise in 683 surface temperature is experienced earlier and is slightly more rapid with the surface frost 684 occurrence showing the same trend. At $75^{\circ} \mathrm{S}$, the surface temperature plateau is reached at $\mathrm{L}_{\mathrm{s}}$ $685 \sim 280^{\circ}$, whereas at $67^{\circ} \mathrm{S}$ it is reached at $\mathrm{L}_{s} \sim 240^{\circ}$.

686 Figure 12 shows the timing of the gully activity alongside observations of seasonal surface frost 687 cover from HiRISE. In almost all cases, the activity occurs at the very end of the surface defrosting. 688 The three exceptions are gully 3 in MY 29 and 31, and gully 7 in MY 31, where activity is earlier 689 in the year. These exceptions show the same type of activities compared to the others, but gully 3 690 is the only active gully in the study region orientated due north, which implies an earlier, more 691 intense sun exposure and earlier defrosting. This is the likely explanation for the relatively early 692 activity compared to the other active gullies. The active gully was investigated by Raack et al. 693 (2015) and shows clear headwall erosion of material in the source region (Figure 5). Gully 7 shows 694 an early block movement in MY 31 and this was the only active block movement whose timing 695 could be constrained in time. All other block movements appear in regions where a high-resolution 696 multi-temporal coverage was not available (see Supplementary Table 01). Therefore, whether 697 block movements systematically occur before the flow-like features in the study region could 698 neither be excluded nor confirmed.

699 Seasonal frost coverage of the study region was easy to identify. During winter and early beginning 700 of spring, the surface appeared relatively bright and dark defrosting spots are visible mainly on 701 dunes. This bright appearance is probably caused by the redeposition of $\mathrm{CO}_{2}$ frost on top of the 702 generally translucent slab ice cover. Later, while the defrosting process is occurring (mid to end 703 of spring), only small bright icy patches on the generally defrosted surface are clearly visible. Dark 704 defrosting spots appear on all dark dunes within the study region. 


\section{Solar longitude $\left({ }^{\circ}\right)$}

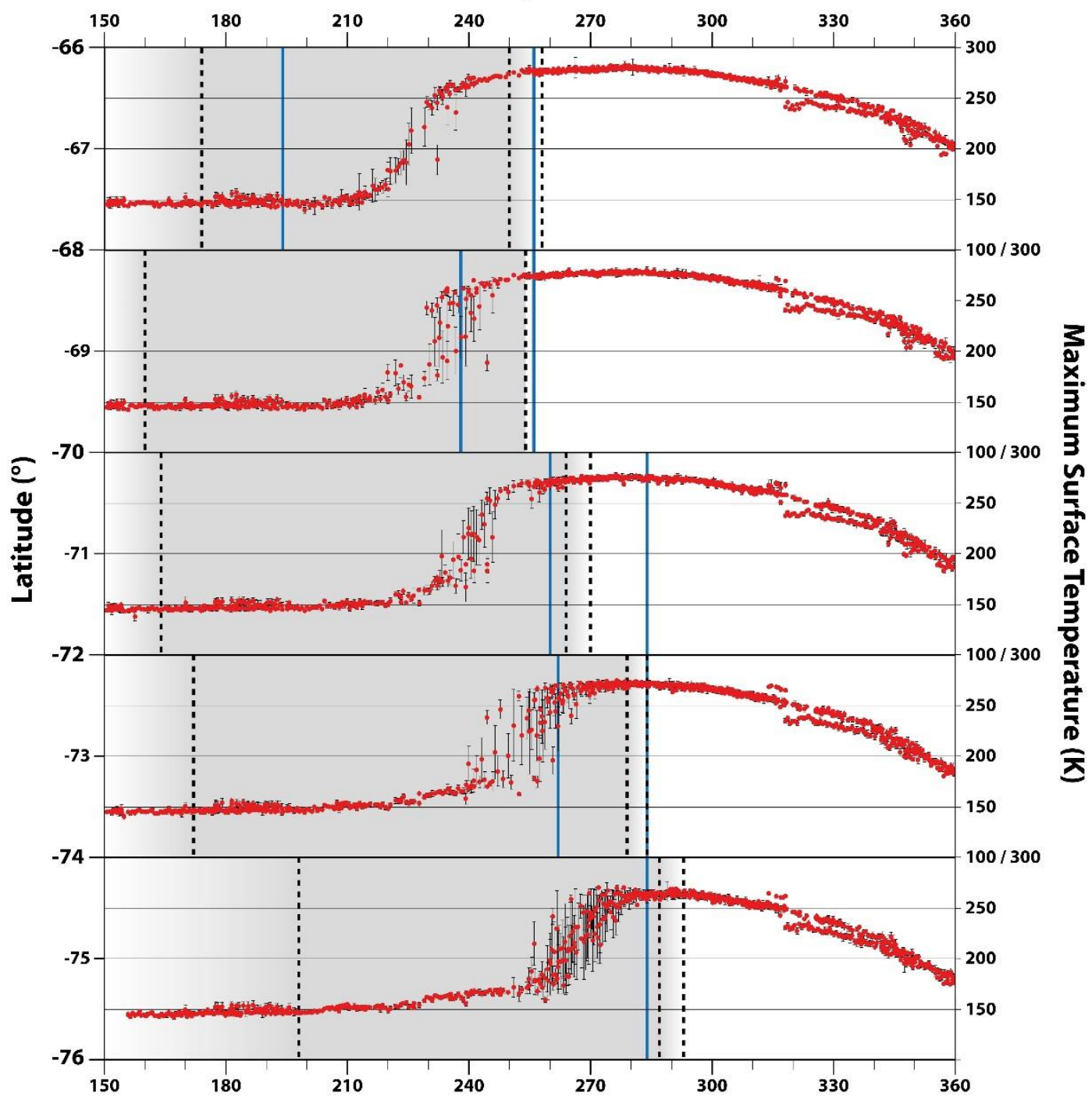

706 Figure 11: Schematic diagram of the average annual defrosting of the study region. Solar 707 longitudes from end of winter ( $\left.\operatorname{Ls} 150^{\circ}-180^{\circ}\right)$, spring (Ls $\left.180^{\circ}-270^{\circ}\right)$, to summer $\left(\operatorname{Ls} 270^{\circ}-\right.$ $708360^{\circ}$ ) of the southern hemisphere vs. latitude of the study region (left, subdivided into areas of $2^{\circ}$ ) 709 and vs. maximum surface temperatures (right, TES) of the study region within subdivided regions.

710 The grey bar within each subdivision represents the surface defrosting observed on CTX datasets

711 of MY 28-34. The first dashed black line represents the timing of the first available image (frosted

712 surfaces), the second dashed black line represents the timing of the last image with identifiable 713 patches of surface frost, and the third and last dashed black line represents the timing of the first 
714 image without any surface frost. The blue lines represent the timing of defrosting observed on

715 HRSC imagery. The first blue line represents the timing of the last image with identified ice on

716 the surface, the second line represents the timing of the first image without any surface frost. The

717 red dots represent maximum daytime surface temperatures measured by TES of MY 24 to 26. The

718 individual dots represent the average of all taken TES measurements at the same time (same solar

719 longitude) with standard deviation (thin black "error" lines).

720

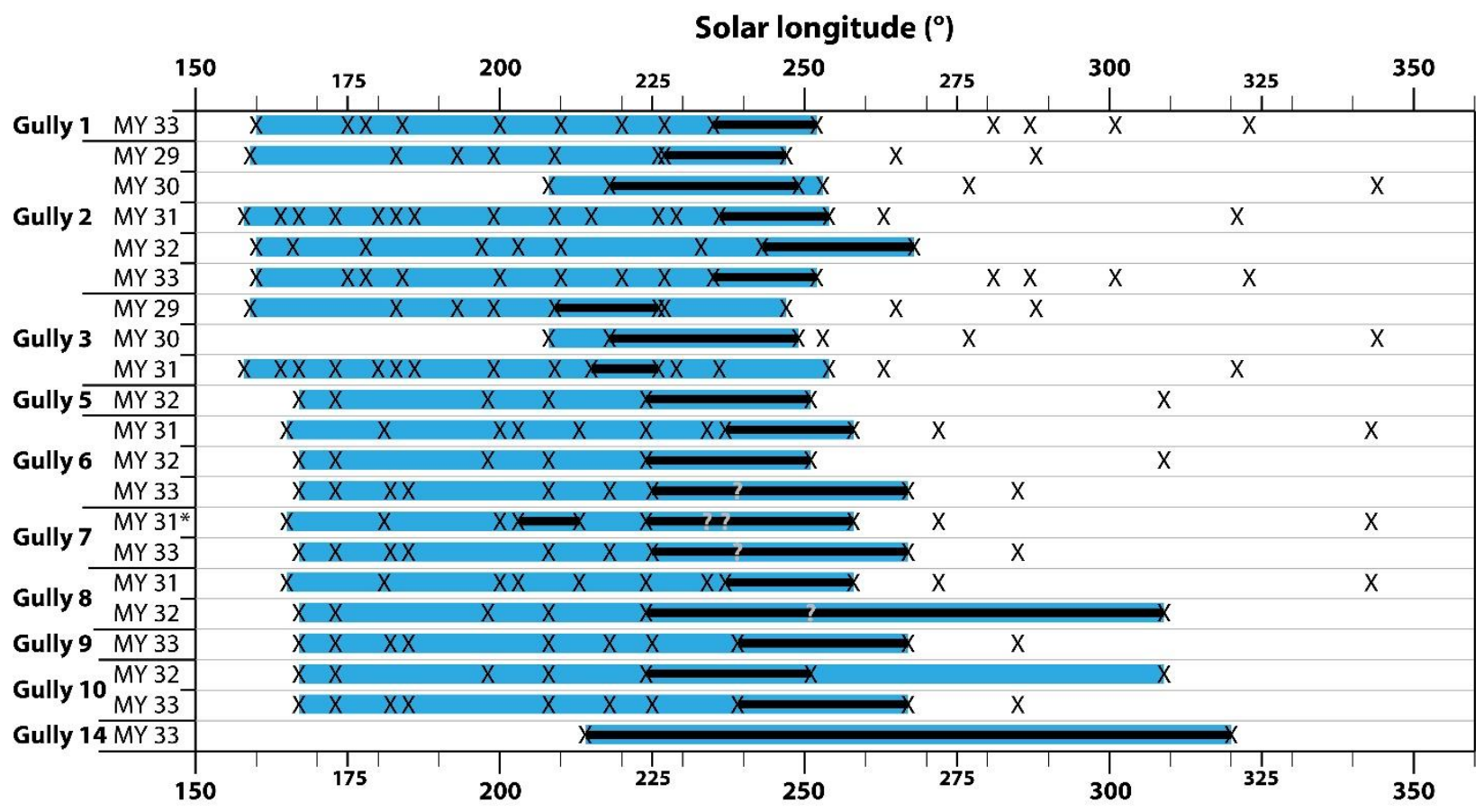

721 Figure 12: Diagram of 10 different gullies with contemporary flow-like features activity (except

722 gully 7 in MY 31, marked with an asterisk, where both activities within the year are related to

723 block movements), which could be narrowed down to an exact timing within one martian year

724 based on HiRISE imagery. All gullies are between $-68.4^{\circ}$ and $-70.7^{\circ} \mathrm{S}$ (see Supplementary Table

725 01). The activity of the other 26 identified active gullies in the study region could not be

726 constrained within one martian year. Some of the 10 gullies show periodic activity within different

727 martian years (y-axis). The crosses represent single HiRISE images, as well as the grey question

728 marks of gullies 6 to 8 do. However, the question marks represent images where the identification 
729 of changes in previous images could not be confirmed due to lower resolutions, atmospheric dust 730 coverage, adverse insolation, and/or extensive surface albedo changes caused by surface 731 defrosting. The blue bars represent the identified surface frost coverage from the beginning of 732 surface frost (beginning of blue bar) to the first image without any identifiable surface frost (end 733 of blue bar). Black bars represent identified activity from between the "before" and "after" HiRISE 734 images.
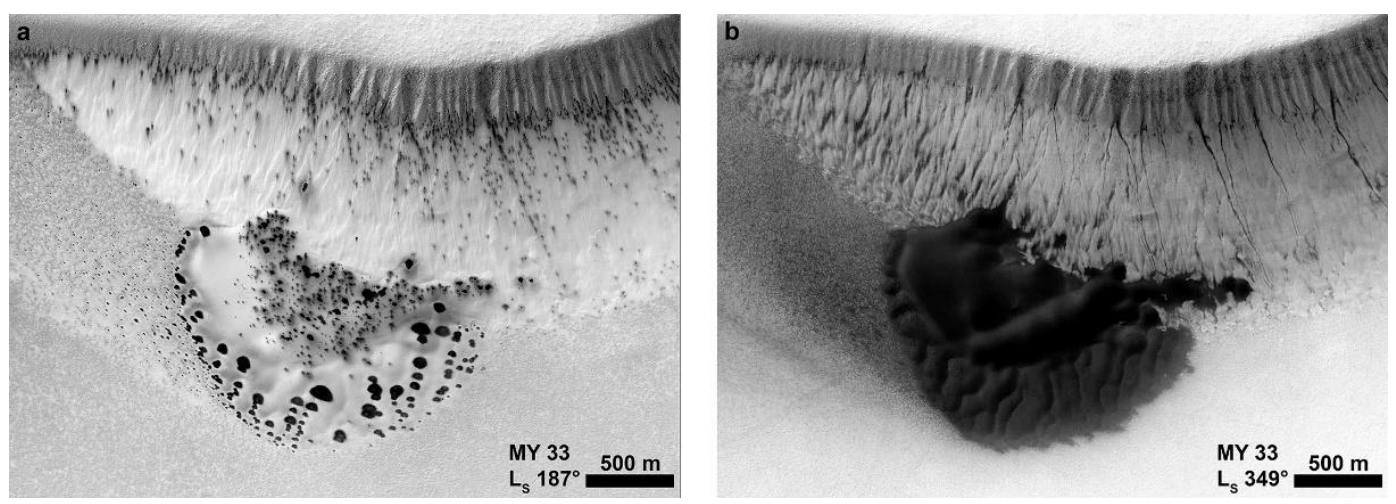

736 Figure 13: (a) A gullied slope with adjacent dark dune field in MY 33 during defrosting at the 737 beginning of spring (Ls $\left.187^{\circ}\right)$ with numerous dark defrosting spots. (b) The same location after 738 complete defrosting with an ice-free surface during summer ( Ls $_{3} 49^{\circ}$ ). Notice that the dark 739 defrosting spots shown in (a) only occur in regions with a sandy surface (dark dune, windblown 740 sand on the eastern side of the dune, and the gullied slope with preferentially loose material. 741 HiRISE-images (a) EPS_046749_1085 and (b) EPS_050230_1080. North is up in all images. 

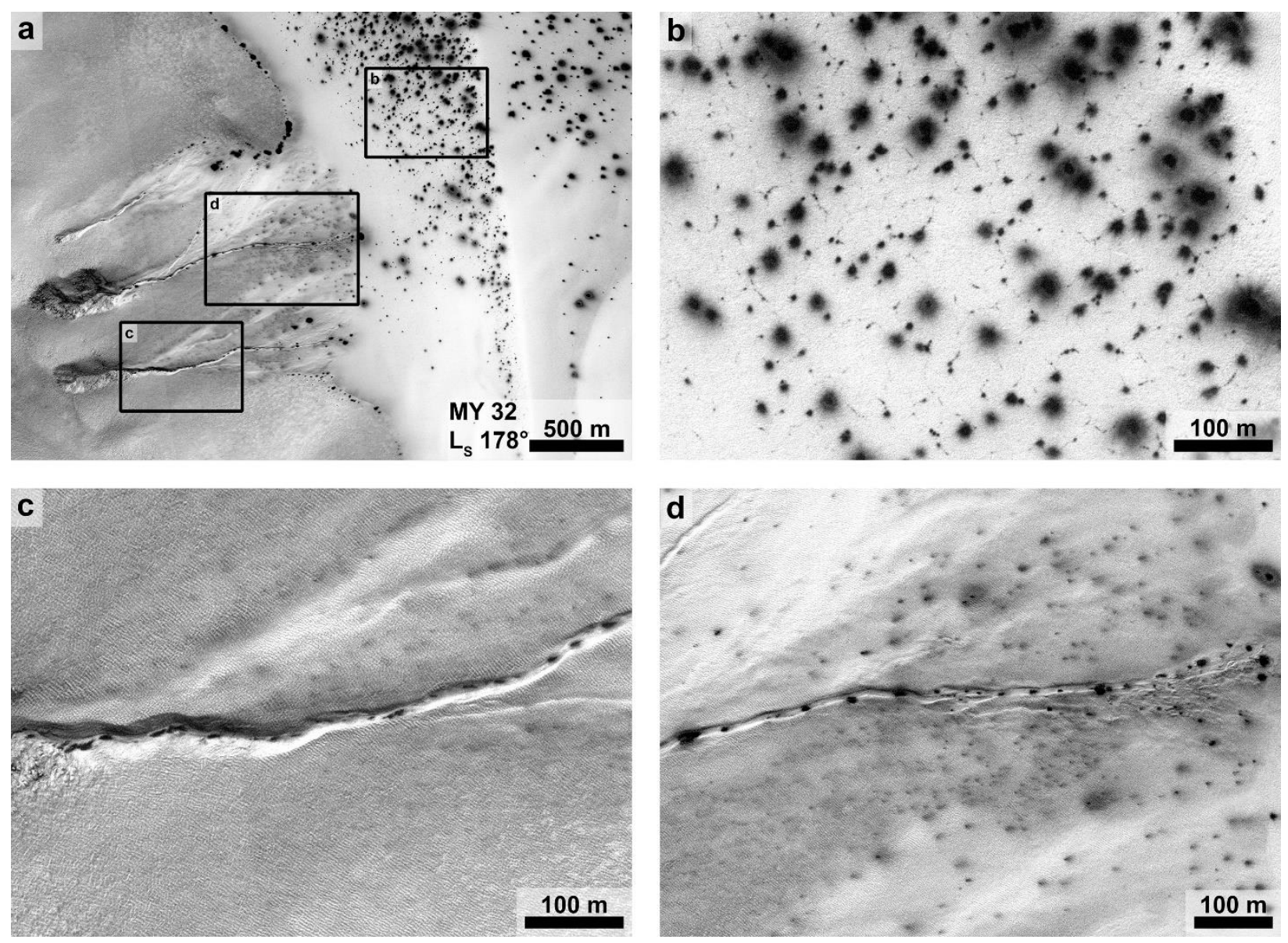

Figure 14: Examples of dark defrosting spots in the study region. (a) Overview of an east-facing slope with three gullies. The gully aprons run into a dune field, which is within a polar pit. (b)

Detail of the dune crest with several dark defrosting spots as well as visible cracks in the slab ice.

The image was taken at the end of winter/beginning of spring (Ls 178 $)$ and the dune appears bright probably due to redeposition of $\mathrm{CO}_{2}$ frost on top on the translucent seasonal $\mathrm{CO}_{2} \mathrm{slab}$ ice cover (comparable to dune field in Figure 8). (c) Detail of one of the gully channels and (d) one of the gully channels with adjacent apron. Dark spots are present within the gully channels and on the aprons, while they are absent on the adjacent hillslopes. This could be caused by the lack of

751 fine material on the slopes, a lack of sufficiently sintered slab ice or different thermal contrasts. 


\section{Discussion}

\subsection{Dark spots and flow-like streaks}

Prior and during the activity of the flow-features in the gullies in Sisyphi Cavi the appearance of dark spots and flow-like streaks are observed on the surface, which do not change the topography. To obviate possible confusion we named these small features emanating from dark defrosting spots "dark flow-like streaks", while "dark flow-like features" refer to the present-day activity of gullies with observable sediment transport. The phenomenon of dark spots was first observed by Cantor et al. (2002) and is well described in the literature (e.g., Piqueux et al, 2003; Kieffer et al., 2006; Horváth et al., 2009; Hansen et al., 2010; Pilorget et al., 2011; Martínez et al., 2012; Jouannic et al., 2019). The dark spots are formed by basal sublimation of seasonal translucent slab-ice (Figure 13; e.g., Piqueux et al., 2003; Kieffer et al., 2006). The basal sublimation leads to overpressure under the ice, leading to the formation of cracks within the ice (see Figure 14b; Portyankina et al., 2012). Through these cracks degassing occurs and dust/sand particles are entrained and redeposited on the surface of the ice (e.g., Piqueux et al., 2003; Kieffer et al., 2006; Portyankina et al., 2012) (Figure 13, 14). If the surface is inclined, the sediment can move downslope forming dark flow-like streaks (e.g., Horváth et al., 2009; Kereszturi et al., 2009, 2010, 2011; Gardin et al., 2010; Hansen et al., 2010, 2012; Jouannic et al., 2019), which are observed in our study region during spring. Within the study region, dark spots are only observed on dark dunes and on gullies (non-active and active ones), particularly within the gully channel and on aprons (Figure 14). Based on the same timing of activity and very similar morphologic features (Figure 14), we infer that the same formation mechanism is responsible for the dark spots and flows in the study region, on dunes as well as in gullies. Thus, these two substrates may have similar properties that differ from the surrounding terrain in order to explain the fact that the dark spots/flows are only found 
777 on the dunes and gullies. This implies that dunes, gully channels, and aprons are formed of fine

778 grained material such as sand and dust, which can be mobilized. It could also imply that these

779 substrates somehow favor the formation of slab ice and/or the basal heating.

780 Such dark flow-like streaks have been observed on other gullies, notably the linear gullies on the

781 Russell crater megadune (Gardin et al., 2010; Jouannic et al., 2019) and also on classical gullies

782 in Sisyphi Cavi by Dundas et al. (2019) or in the mid-latitudes by Costard et al. (2007). Dundas et

783 al. (2019) presented a gully as an example for defrosting flows in a polar pit gully which was also

784 investigated in our study. They did not detect changes in topography after the flow disappeared.

785 However, our new observations reveal very small topographic changes, probably missed in the

786 Dundas et al. (2019) study due to fewer available HiRISE images.

787

788

789

790

791

792

793

794

795

796

797

798

799

\subsection{Dark flow-like features}

We have shown that at the very end of defrosting of the seasonal $\mathrm{CO}_{2}$ surface ice, flow-like features occur, which modify the topography of the gullies in Sisyphi Cavi. These flows run out onto slopes of $10-15^{\circ}$ (Figure 8 ), hence require some degree of fluidization. Similar flow-like features have been observed in gullies imaged in the shadows of impact craters in three craters in the midlatitudes (32-38 $\mathrm{S}$; Dundas et al., 2019). As a consequence of the less frequent monitoring of gully-sites outside the polar regions, changes observed in mid-latitude martian gullies may also have happened over frost. However, this has not yet been documented in images because they were not captured at the right time and cadence. In contrast to the Sisyphi Cavi gullies, in the midlatitudes flow-like features were only observed on south-facing slopes. The timing of activity in Sisyphi Cavi coincides with activity associated with linear gullies on martian sand dunes (Pasquon et al., 2016; Jouannic et al., 2019). However, in this case the activity seems to originate from the 
800 frosted areas and propagate over unfrosted areas (Diniega et al., 2013; Jouannic et al., 2019) and 801 again this activity is predominantly on south-facing slopes. Classic gullies on sand dunes have a 802 more complex behavior with activity continuing throughout winter (Diniega et al., 2010; Pasquon 803 et al., 2019a,b).

804 The flow-like features occur when the $\mathrm{CO}_{2}$ seasonal deposit is becoming thin and discontinuous. 805 This is also visible in the thermal datasets (Figure 11) where the temperature variability of the 806 standard deviation during the sublimation phase is very high. This is the case when ice covered 807 and non-ice covered surfaces are measured at the same time. 808 The formation mechanism of dark flows via pressurized debris flows underneath the slab ice 809 proposed by Pilorget and Forget (2016) is unlikely in Sisyphy Cavi. Raack et al. (2015) showed 810 with spectral and thermal investigations and numerical modelling that the dark flows are on top of 811 the ice and not underneath it, at least for the most active gully in Sisyphi Cavi and our additional 812 image observations support this earlier work.

813 Instead, a modified Cedillo-Flores et al. (2011) model where relatively hot sediments are 814 transported by sublimation of the $\mathrm{CO}_{2}$ ices underneath the flow seems a more likely scenario. The 815 fact that the deposits are preserved into the summer months leads us to the conclusion that either 816 the underlying $\mathrm{CO}_{2}$ surface frost is relatively thin and/or the dark flows are turbulent and consist 817 of a mixture of some ice and dry material, which erodes the underlying thin surface frost. If large 818 quantities of $\mathrm{CO}_{2}$ ice were located either under or within the transported debris, their subsequent 819 sublimation would disturb and change the morphology of the deposits over time. De Haas et al. 820 (2019) calculated that only very small volumetric fractions of $\mathrm{CO}_{2}(<<1 \%)$ are required to fluidize 821 a flow, hence a thin surface frost should be adequate to fluidize the flow. 
822 The number of active gullies in Sisyphi Cavi is a small proportion of the whole population: 7 of 82325 sites are active, i.e., only 35 of 2,067 individual gullies on multi-temporal HiRISE-images

824 (about $1.7 \%$ ). This value is even lower when only flow-like features without block movements 825 are included $(n=22$, which is about $1 \%)$. Even though some of the gullies are active annually, 826 many only showed one or two events during the time of image acquisition. This shows that 827 contemporary activity of gullies in this region is rare. To-date, about $35 \%$ of all gullies in the 828 study region have multi-temporal coverage. Some of them only have coverage by two multi829 temporal images, which makes a visual identification of changes even more challenging.

830 Active gullies in Sisyphi Cavi could have long recurrence times, similar to debris flows on Earth 831 (e.g., de Haas et al., 2015), but a longer baseline of observation would be needed to substantiate 832 this hypothesis. We found no topographic or other factor (e.g., differential movement of the 833 headwall) that could explain why certain gullies are active (often repeatedly) and others are not, 834 even within those gullies located at the same site. Similarly to debris flows, such events could be 835 limited by the union of sufficient accumulation of loose material (via jetting processes like dark 836 spots/flows?) and rare climatic events that put the system in motion. We now consider whether the 837 activity seen today, integrated over a long time period, could be sufficient to explain the whole 838 gully population in Sisyphi Cavi. The flow-like features that we observed have a sufficient runout 839 to transport material to the base of the gully-fans, hence are capable of explaining the spatial extent 840 of the gullies. Taking into account imaging bias, the flow-like features we observed have a range 841 and variety of orientations that suggest similar events could occur on the whole range of slope 842 orientations in Sisyphi Cavi, although more data would be needed in the under-imaged east-facing 843 orientations to verify this (Figure 9). 
844 For gullies \#1, \#2, and \#3 we calculated the area covered by deposits during the time of 845 observation, which ranged between $\sim 600$ and $\sim 2,800 \mathrm{~m}^{2}$ per MY. Conservatively assuming a 0.5

846 m thickness for these deposits (Raack et al., 2015) results in volumes of between $\sim 300$ and $\sim 1,400$

$847 \mathrm{~m}^{3}$ per MY. We used the publicly available HiRISE DTM derived from the stereo pair 848 ESP_013097_1115 and ESP_013585_1115 to measure the alcove volumes of the gullies. We 849 removed / masked the values of the DTM inside 19 alcoves and linearly interpolated over the gap 850 then differenced with the original DTM (e.g., Conway and Balme, 2014) to find alcove volumes 851 between 32,000 and 2,819,000 $\mathrm{m}^{3}$ (average 956,000 $\mathrm{m}^{3}$ ). Assuming a constant rate of activity, we 852 find that whole gullies could be formed in decades to several tens of thousands of Mars years $853(\sim 4,000$ Mars years for an average alcove with an average level of activity). As cycles of obliquity 854 have a dominant frequency of $120 \mathrm{ka}$, eccentricity $95 \mathrm{ka}$, and precession $51 \mathrm{ka}$ (Ward, 1974; 1979; 855 1992), our estimated gully formation times fall into times when the climate would not have differed 856 substantially from the present-day climate. Hence, it is realistic that processes similar to those 857 active at the present-day could explain the formation of the entire gully-landform without invoking 858 other mechanisms. However, some gully alcoves are filled with presumably aeolian sedimented 859 ice-rich mantle material (e.g., Mustard et al, 2001; Raack et al., 2012; Figure 5). This ice-rich 860 mantle appears uncratered and other studies estimated maximum ages of 20 Ma for mid861 latitudinal locations (Raack et al., 2012) and $~ 3-5$ Ma near the poles (55-60 S) (Willmes et al., 862 2012). This suggests that gully formation has been ongoing over much longer timescales than 863 recorded by the most recent active gullies, but could still be dependent on conditions similar to the 864 present-day for their formation (indeed conditions conducive for mantle emplacement seem to be 865 non-conducive for gully-formation). 


\subsection{Block movements}

868 We could only constrain the timing of one of the 16 block movements observed during spring,

869 prior to the activity of the flow-like features. Block movements were sometimes spatially

870 associated with and sometimes independent of the flow-like features we observed. All movements

871 occurred in the alcove areas of the gullies where slopes are typically $>20^{\circ}$ (Figure 8 ) and were

872 usually of a few meters, leaving no track. Sometimes the block just moved $\sim 1-2$ meters, consistent

873 with just toppling over. It is tempting to link these movements to the flows associated with the

874 gullies, yet no blocks are found in the deposits and similar block movements have been reported

875 in areas without gullies. Dundas et al. (2019) found block movements of meters to tens of meters

876 on slopes of typically $25-35^{\circ}$ in craters in the northern hemisphere of which the majority occurred

877 in winter and two occurred in summer. Dundas et al. (2019) argued that because similar block

878 movements are not observed at equatorial latitudes, some aspect of the seasonal cycle encourages

879 these types of movement. They suggested that thermal contraction/expansion of underlying ground

880 ice could disturb blocks or even slight changes in the ground ice distribution driven by seasonal

881 temperature changes. They considered loading or other disturbances by the seasonal ice as less

882 likely because some movements were observed in summer. Given that we only have the timing for

883 one of the movements in our dataset, it is currently impossible to move beyond the hypotheses

884 suggested by Dundas et al. (2019).

885

886 5. Conclusions

887 Based on various visual and thermal remote sensing data, especially high-resolution multi888 temporal images, we identified and analyzed multiple contemporary active gullies within Sisyphi

889 Cavi. On the basis of our study we conclude: 
(1) At least $\sim 1.7 \%$ of all gullies observed with HiRISE show present-day activity (flow-like features and/or block movements). This is a minimum value as some activity could be overlooked and the required number of multi-temporal images for a complete investigation in all martian years is not available for all regions. Nevertheless, the number of active flowlike features (about $1 \%$ of all investigated gullies) is very low which shows that contemporary gully activity in Sisyphi Cavi is generally rare.

(2) All observed gully activity took place during the end of spring at the end of the seasonal defrosting. During this season, the highest surface temperatures for a partially ice-covered surface were observed. During this time, dark defrosting spots on dunes and gullies were most prevalent.

(3) The origin of the transported material are the alcoves and small layers on the flanks of gully channels. We made the first observations of headwall erosion of gully alcoves. Material accumulated within the gully channel and moved down in one catastrophic flow event.

(4) The preferred triggering mechanism for present-day gully activity in Sisyphi Cavi are flows of dry material over seasonal slab ice (comparable to dark spots/flows). It is possible, that the material flowing on top of the ice eroded the underlying ice and formed a mixture of dry material and ice, which was then transported together downslope, fluidizing the flow. It is estimated that the ice thickness at the time of dark flow-like feature appearance was relatively thin, which is consistent with the observation that this activity is linked to the last defrosting stages. The triggering factor of the movement of blocks remains unclear due to the lack of multi-temporal images.

(5) We found the orientation of active gullies to be broadly consistent with the general population and using volume balance arguments, calculated that some of the active gullies 
could have been formed within decades to several tens of thousands of MY. This implies that the gullies in Sisyphi Cavi could have been formed in their entirety by processes similar to these active at the present day.

916

\section{Acknowledgments}

918 JR and TH are funded by the German Aerospace Agency (DLR) by the Grant \#50QM1801. SJC 919 is grateful to the French Space Agency CNES for funding her HiRISE and CaSSIS related work. 920 AJ is funded by the Swedish National Space Agency SNSA. We thank Dennis Reiss for many 921 fruitful discussions in the initial stage of this survey. The used DIC code is open-source and can 922 be downloaded from: https://github.com/bickelmps/DIC_FFT_ETHZ. We are grateful for very 923 constructive reviews from J. Dickson and an anonymous expert.

924

925 References

926 Ayoub, F., Leprince, S., Avouac, J.-P., 2009. Co-Registration and correlation of aerial photographs 927 928 929

Beyer, R.A., Alexandrov, O., McMichael, S., 2018. The Ames Stereo Pipeline: NASA's Open Source Software for Deriving and Processing Terrain Data. Earth Space Sci. 5 (9), 537-548. https://doi.org/10.1029/2018EA000409. 
934 Bickel, V.T., Manconi, A., Amann, F., 2018. Quantitative assessment of digital image correlation 935 methods to detect and monitor surface displacements of large slope instabilities. Remote 936 Sens. 10, 865. https://doi.org/10.3390/rs10060865.

937

938

939

Bridges, N.T. et al., 2012. Earth-like sand fluxes on Mars. Nature 485, 339-342. https://doi.org/10.1038/nature11022.

940

941 Cantor, B., Malin, M., Edgett, K.S., 2002. Multiyear Mars Orbiter Camera (MOC) observations 942 of repeated Martian weather phenomena during the northern summer season. J. Geophys. Res. 107 (E3), 5014. https://doi.org/10.1029/2001JE001588.

944

945

Casu, F., Manconi, A., Pepe, A., Lanari, R., 2011. Deformation Time-Series Generation in Areas 946 947 Characterized by Large Displacement Dynamics: The SAR Amplitude Pixel-Offset SBAS Technique. Trans. Geosci. Remote Sens. 49, 7, 2752-2763. https://doi.org/10.1109/TGRS.2010.2104325.

949

950

951

952

Cedillo-Flores, Y., Treiman, A.H., Lasue, J., Clifford, S.M., 2011. $\mathrm{CO}_{2}$ gas fluidization in the initiation and formation of martian polar gullies. Geophys. Res. Lett. 38, L21202. https://doi.org/10.1029/2011GL049403.

953

954 Christensen, P.R. et al., 2001. Mars Global Surveyor Thermal Emission Spectrometer experiment: 955 Investigation description and surface science results. J. Geophys. Res. 106 (E10), 23823956 23872. https://doi.org/10.1029/2000JE001370. 
958 Christensen, P.R. et al., 2004. The Thermal Emission Imaging System (THEMIS) fort he Mars 2001 Odyssey mission. Space Sci. Rev. 110, 85-130. 960 https://doi.org/10.1023/B:SPAC.0000021008.16305.94.

961

962

963

Conway, S.J. and Balme, M.R., 2014. Decameter thick remnant glacial ice deposits on Mars. Geophy. Res. Lett., 41(15), 5402-5409. https://doi.org/10.1002/2014GL060314.

964

965

Conway, S.J., Lamb, M.P., Balme, M.R., Towner, M.C., Murray, J.B., 2011. Enhanced runout and 966 erosion by overland flow at low pressure and sub-freezing conditions: Experiments and application to Mars. Icarus 211, 443-457. https://doi.org/10.1016/j.icarus.2010.08.026.

968

969

970

Conway, S.J., Balme, M.R., Kreslavsky, M.A., Murray, J.B., Towner, M.C., 2015. The comparison of topographic long profiles of gullies on Earth to gullies on Mars: A signal of water on Mars. Icarus 253, 189-204. https://doi.org/10.1016/j.icarus.2015.03.009.

972

973 Conway, S.J., Harrison, T.N., Soare, R.J., Britton, A.W., Steele, L.J., 2019. New slope-normalized 974 975 global gully density and orientation maps for Mars. Geol. Soc. London Spec. Publ. 467, 187197. https://doi.org/10.1144/SP467.3.

976

977 Costard, F., Mangold, N., Baratoux, D., Forget, F., 2007. Current Gully Activity: Dry Avalanches 978 at Seasonal Defrosting as Seen on HiRise Images. Seventh International Conference on 979 Mars, Contrib. No. 3133. 
981

982

983

984

985

986

987

988

989

990

991

992

993

994

995

996

997

998

999

1000

1001

1002 de Haas, T. et al., 2015. Earth-like aqueous debris-flow activity on Mars at high orbital obliquity in the last million years. Nat. Comm. 6, 7543. https://doi.org/10.1038/ncomms8543.

de Haas, T. et al., 2019. Initiation and flow conditions of contemporary flows in Martian gullies. J. Geophy. R.: Planets 124(8), 2246-2271. https://doi.org/10.1029/2018JE005899.

Dickson, J.L. and Head J.W., 2009. The formation and evolution of youthful gullies on Mars: Gullies as the late-stage phase of Mars' most recent ice age. Icarus 204, 63-86. https://doi.org/10.1016/j.icarus.2009.06.018.

Dickson, J.L., Head, J.W., Kreslavsky, M., 2007. Martian gullies in the southern mid-latitudes of Mars: Evidence for climate-controlled formation of young fluvial features based upon local and global topography. Icarus 188, 315-323. https://doi.org/10.1016/j.icarus.2006.11.020.

Dickson, J.L., Kerber, L.A., Fassett, C.I., Ehlmann, B.L., 2018. A global, blended CTX mosaic of Mars with vectorized seam mapping: A new mosaicking pipeline using principles of nondestructive image editing. 49 $9^{\text {th }}$ Lunar and Planetary Science Conference, Contrib. No. 2083.

Diniega, S., Byrne, S., Bridges, N.T., Dundas, C.M., McEwen, A.S., 2010. Seasonality of presentday Martian dune-gully activity. Geology 38, 11, 1047-1050. https://doi.org/10.1030/G31287.1. 
1003 Diniega, S. et al., 2013. A new dry hypothesis for the formation of martian linear gullies. Icarus 225, 526-237. http://dx.doi.org/10.1016/j.icarus.2013.04.006.

1005

1006

1007

1008

1009

1010

1011

1012

1013

1014

1015

1016

1017

1018

1019

1020

1021

1022

1023

Dundas, C.M., McEwen, A.S., Diniega, S., Byrne, S., Martinez-Alonso, S., 2010. New and recent gully activity on Mars as seen by HiRISE. Geophys. Res. Lett. 37, L07202, https://doi.org/10.1029/2009GL041351.

Dundas, C.M., Diniega, S., Hansen, C.J., Byrne, S., McEwen, A.S., 2012. Seasonal activity and morphological changes in martian gullies. Icarus 220, 124-143. http://dx.doi.org/10.1016/j.icarus.2012.04.005.

Dundas, C.M., Diniega, S., McEwen, A.S., 2015. Long-term monitoring of martian gully formation and evolution with MRO/HiRISE. Icarus 251, 244-263. http://dx.doi.org/10.1016/j.icarus.2014.05.013.

Dundas, C.M. et al., 2019. The formation of gullies on Mars today. Geol. Soc. London Spec. Publ. 467, 67-94. https://doi.org/10.1144/SP467.5.

Gardin, E., Allemand, P., Quantin, C., Thollot, P., 2010. Defrosting, dark flow features, and dune activity on Mars: Example in Russell crater. J. Geophys. Res. 115, E06016. https://doi.org/10.1029/2009JE003515. 
1025 Ghatan, G.J. and Head, J.W., 2002. Candidate subglacial volcanoes in the south polar region of 1026 Mars: Morphology, morphometry, and eruption conditions. J. Geophys. Res. 107. https://doi.org/10.1029/2001JE001519.

1028

1029

Grindrod, P.M., Hollingsworth, J., Ayoub, F., Hunt, S.A., 2018. The Search for Active Marsquakes Using Subpixel Coregistration and Correlation: Best Practice and First Results. J. Geophys.

Hansen, C.J. et al., 2010. HiRISE observations of gas sublimation-driven activity in Mars' 1034 southern polar regions: I. Erosion of the surface. Icarus 205, 283-295. https://doi.org/10.1016/j.icarus.2009.07.021.

1036

Hansen, C.J. et al., 2012. Observations of the northern seasonal polar cap on Mars: I. Spring 1039 sublimation activity and and processes. Icarus 225, 881-897. https://doi.org/10.1016/j.icarus.2012.09.024.

1040

Harrison, T.N., Osinski, G.R., Tornabene, L.L., Jones, E., 2015. Global documentation of gullies with the Mars Reconnaissance Orbiter Context Camera and implications for their formation. Icarus 252, 236-254. https://doi.org/10.1016/j.icarus.2015.01.022.

Head, J.W., 2000. Tests for ancient polar deposits on Mars: Assessment of morphology and 1046 topographic relationships of large pits (Angusti and Sisyphi Cavi) using MOLA data. Lunar Planet. Sci. XXXI, abstract 1118. 
1049 Heid, T. and Kääb, A., 2012. Evaluation of existing image matching methods for deriving glacier 1050 surface displacements globally from optical satellite imagery. Remote Sens. Environ. 118, 1051 339-355. https://doi.org/10.1016/j.rse.2011.11.024.

1052

1053 Herny, C. et al., 2019. Downslope sediment transport by boiling liquid water under Mars-like 1054 conditions: experiments and potential implications for Martian gullies. Geol. Soc. London Spec. Publ. 467, 373-410. https://doi.org/10.1144/SP467.10.

1056

1057

1058

Heyer, T. et al., 2018. The Multi-Temporal Database of Planetary Image Data (MUTED): A webbased tool for studying dynamic Mars. Planet. Space Sci. 159, 56-65. 1059 https://doi.org/10.1016/j.pss.2018.04.015.

1060

1061

1062

Hoffman, N., 2002. Active polar gullies on Mars and the role of carbon dioxide. Astrobiology 2, 313-323. https://doi.org/10.1089/153110702762027899.

1063

1064

1065

Horváth, A. et al., 2009. Analysis of Dark Albedo Features on a Southern Polar Dune Field on Mars. Astrobiology 9, 90-103. https://doi.org/10.1089/ast.2007.0212.

1066

1067 Howard, A.D., 1981. Etched plains and braided ridges of the south polar region of Mars: Features 1068 produced by basal melting of ground ice? NASA Technical Memorandum 84211, 1069 Washington DC, p286.

1070 
1071 Hugenholtz, C.H., 2008. Frosted granular flow: a new hypothesis for mass wasting in Martian 1072 gullies. Icarus 197, 65-72. https://doi.org/10.1016/j.icarus.2008.04.010.

1073

1074

1075

1076

1077

1078

1079

1080

1081

1082

1083

1084

1085

1086

1087

1088

1089

1090

1091

Ishii, T. and Sasaki, S., 2004. Formation of recent martian gullies by avalanches of $\mathrm{CO}_{2}$ frost. Lunar Planet. Sci. XXXV, abstract 1556.

Ishii, T. et al., 2006. Constraints on the formation of gullies on Mars: a possibility of the formation of gullies by avalanches of granular $\mathrm{CO}_{2}$ ice particles. Lunar Planet. Sci. XXXVII, abstract 1646.

Jaumann, R. et al., 2007. The high-resolution stereo camera (HRSC) experiment on Mars Express: Instrument aspects and experiment conduct from interplanetary cruise through the nominal mission. Planet. Space Sci. 55, 928-952. https://doi.org/10.1016/j.pss.2006.12.003.

Jouannic, G. et al., 2012. Morphological and mechanical characterization of gullies in a periglacial environment: The case of the Russell crater dune (Mars). Planet. Space Sci. 71, 38-54. http://dx.doi.org/10.1016/j.pss.2012.07.005.

Jouannic, G. et al., 2019. Morphological characterization of landforms produced by springtime seasonal activity on Russel Crater megadune, Mars. Geol. Soc. London Spec. Publ. 467, 115-144. https://doi.org/10.1144/SP467.16. 
1093 Kereszturi, A. et al., 2009. Recent rheologic processes on dark polar dunes of Mars: Driven by 1094 interfacial water? Icarus 201, 492-503. https://doi.org/10.1016/j.icarus.2009.01.014.

1095

1096

Kereszturi, A. et al., 2010. Indications of brine related local seepage phenomena of the northern 1097 hemisphere of Mars. Icarus 207, 149-164. https://doi.org/10.1016/j.icarus.2009.10.0142.

1098

1099

Kereszturi, A., Vincendon, M., Schmidt, F., 2011. Water ice in the dark dune spots of Richardson 1100 crater on Mars. Planet. Space Sci. 59, 26-42. https://doi.org/10.1016/j.pss.2010.10.015.

1101

1102

1103

Kieffer, H.H., Christensen, P.R., Titus, T.N., 2006. $\mathrm{CO}_{2}$ jets formed by sublimation beneath translucent slab ice in Mars' seasonal south polar cap. Nature 772, 793-796.

1104 https://doi.org/10.1038/nature04945.

1105

1106

Kirk, R.L. et al., 2008. Ultrahigh resolution topographic mapping of Mars with MRO HiRISE stereo images: Meter-scale slopes of candidate Phoenix landing sites. J. Geophys. Res. 113, E00A24. https://doi.org/10.1029/2007JE003000.

1109

Malin, M.C. and Edgett, K.S., 2000. Evidence for Recent Groundwater Seepage and Surface Runoff on Mars. Science 288, 2330. https://doi.org/10.1126/science.288.5475.2330.

1113 Malin, M.C., Edgett, K.S., Posiolova, L.V., McColley, S.M., Noe Dobrea, E.Z., 2006. PresentDay Impact Cratering Rate and Contemporary Gully Activity on Mars. Science 314, 1573. https://doi.org/10.1126/science.1135156. 
1117 Malin, M.C. et al., 2007. Context camera investigation on board the Mars Reconnaissance Orbiter. J. Geophys. Res. 112, E05S04. https://doi.org/10.1029/2006JE002808.

1119

1120 Martínez, G.M. and Renno, N.O., 2013. Water and Brines on Mars: Current Evidence and 1121 Implications for MSL. Space Sci. Rev. 175, 29-51. https://doi.org/10.1007/s11214-0129956-3.

1123

1124

1125

1126

1127

1128

1129

1130

1131

1132

1133

1134

1135

1136

1137

Martínez, G.M., Renno, N.O., Elliott, H.M., 2012. The evolution of the albedo of dark spots observed on Mars polar region. Icarus 221, 816-830. https://doi.org/10.1016/j.icarus.2012.09.008.

McEwen, A.S. et al., 2007a. A Closer Look at Water-Related Geologic Activity on Mars. Science 317, 5848, 1706-1709. https://doi.org/10.1126/science.1143987.

McEwen, A.S. et al., 2007b. Mars Reconnaissance Orbiter's High Resolution Imaging Science Experiment (HiRISE). J. Geophys. Res. 112, E05S02. https://doi.org/10.1029/2005JE002605.

Murray, B.C. et al., 1972. Geological framework of the south polar region of Mars. Icarus 17 (2), 328-345. https://doi.org/10.1016/0019-1035(72)90004-8. 
1138 Musselwhite, D.S., Swindle, T.D., Lunine, J.I., 2001. Liquid $\mathrm{CO}_{2}$ Breakout and the Formation of 1139 Recent Small Gullies on Mars. Geophys. Res. Lett. 28, 7, 1283-1285. 1140 https://doi.org/10.1029/2000GL012496.

1141

1142 Mustard, J.F., Cooper, C.D., Rifkin, M.K., 2001. Evidence for recent climate change on Mars from 1143 1144 1145 1146 1147 1148 1149

1150 1151 1152 1153 1154 1155 1156 1157

1158 Pilorget, C. and Forget, F., 2016. Formation of gullies on Mars by debris flows triggered by $\mathrm{CO}_{2}$ 1159 sublimation. Nat. Geosci. 9, 65-69. https://www.nature.com/articles/ngeo2619. 1160 the identification of yourthul near-surface ground ice. Nature 412, 411-414. https://doi.org/10.1038/35086515.

Pasquon, K., Gargani, J., Massé, M., Conway, S.J., 2016. Present-day formation and seasonal evolution of linear dune gullies on Mars. Icarus 274, 195-210. http://dx.doi.org/10.1016/j.icarus.2016.03.024.

Pasquon, K., et al., 2019a. Are different Martian gully morphologies due to different processes on the Kaiser dune field? Geol. Soc. London Spec. Publ. 467, 145-164. https://doi.org/10.1144/SP467.13.

Pasquon, K. et al., 2019b. Present-day development of gully-channel sinuosity by carbon dioxide gas supported flows on Mars. Icarus 329, 296-313. https://doi.org/10.1016/j.icarus.2019.03.034. 
1161 Pilorget, C., Forget, F., Millour, E., Vincendon, M., Madeleine, J.B., 2011. Dark spots and cold 1162 jets in the polar regions of Mars: New clues form a thermal model of surface $\mathrm{CO}_{2}$ ice. Icarus 213, 131-149. https://doi.org/10.1016/j.icarus.2011.01.031.

1164

1165

1166

1167

Piqueux, S., Byrne, S., Richardson, M.I., 2003. Sublimation of Mars's southern seasonal $\mathrm{CO}_{2}$ ice cap and the formation of spiders. J. Geophys. Res. 108, E8, 5084. https://doi.org/10.1029/2002JE002007.

1168

1169 Portyankina, G., Pommerol, A., Aye, K.-M., Hansen, C.J., Thomas, N., 2012. Polygonal cracks in 1170 the seasonal semi-translucent $\mathrm{CO}_{2}$ ice layer in Martian polar areas. J. Geophys. Res. 117, 1171 E02006. https://doi.org/10.1029/2011JE003917.

1172

1173 Raack, J., Reiss, D., Hiesinger, H., 2012. Gullies and their relationships to the dust-ice mantle in 1174 the northwestern Argyre Basin, Mars. Icarus 219, 129-141. https://doi.org/10.1016/j.icarus.2012.02.025.

1176

1177 Raack, J. et al., 2015. Present-day seasonal gully activity in a south polar pit (Sisyphi Cavi) on 1178 Mars. Icarus 251, 226-243. https://doi.org/10.1016/j.icarus.2014.03.040.

1179

1180 Raack, J. et al., 2017. Water induced sediment levitation enhances downslope transport on Mars. $1181 \quad$ Nature Comm. 8, 1151. https://doi.org/10.1038/s41467-017-01213-z. 
1183 Reiss, D., Erkeling, G., Bauch, K.E., Hiesinger, H., 2010. Evidence for present day gully activity 1184 on the Russell crater dune field, Mars. Geophy. Res. Lett. 37, L06203. 1185 https://doi.org/10.1029/2009GL042192.

1186

1187 Reiss, D. et al., 2016. Dust Devil Tracks. Space Sci. Rev. 203, 143-181. $1188 \quad$ https://doi.org/10.1007/s11214-016-0308-6.

1189

1190 Schorghofer, N. and Edgett, K.S., 2006. Seasonal surface frost at low latitudes on Mars. Icarus 1191 180, 321-334. https://doi.org/10.1016/j.icarus.2005.08.022.

1192

1193 Schorghofer, N, Aharonson, O., Gerstell, M.F. Tatsumi, L., 2007. Three decades of slope streak 1194 activity on Mars. Icarus 191, 132-140. https://doi.org/10.1016/j.icarus.2007.04.026.

1195

1196 Sharp, R.P., 1973. Mars: South polar pits and etched terrain. J. Geophys. Res. 78 (20), 4222-4230. https://doi.org/10.1029/JB078i020p04222.

1198

1199 Steward, S.T. and Nimmo, F., 2002. Surface runoff features on Mars: Testing the carbon dioxide 1200 formation hypotheses. J. Geophys. $\quad$ Res. $107 \quad$ (E9), 5069. 1201 https://doi.org/10.1029/2000JE001465.

1202

1203 Tanaka, K.L. and Scott, D.H., 1987. Geologic map of the polar regions of Mars. USGS Map I1204 1802C. https://doi.org/10.3133/i1802C. 
1206 Thomas, N., Portyankina, G., Hansen, C. J., Pommerol, A., 2011. HiRISE observations of gas

1207

1208

1209

1210

1211

1212

1213

1214

1215

1216

1217

1218

1219

1220

1221

1222

1223

1224

1225

1226

1227

1228 sublimation-driven activity in Mars' southern polar regions: IV. Fluid dynamics models of $\mathrm{CO}_{2}$ jets. Icarus 212, 66-85. https://doi.org/10.1016/j.icarus.2010.12.016

Thomas, N. et al., 2017. The Colour and Stereo Surface Imaging System (CaSSIS) for the ExoMars Trace Gas Orbiter. Space Sci. Rev. 212, 1897. https://doi.org/10.1007/s11214-017-0421-1.

Thomas, P., Squyres, S., Herkenhoff, K., Howard, A., Murray, B., 1992. Polar deposits of Mars. In Mars, ed. H.H. Kieffer, B.M. Jakosky, C.W. Snyder, M.S. Matthews. Tuscon, AZ: University of Arizona Press, pp. 767-795.

Vincendon, M. et al., 2010a. Near-tropical subsurface ice on Mars. Geophys. Res. Lett. 37, L01202. https://doi.org/10.1029/2009GL041426.

Vincendon, M., Forget, F., Mustard, J., 2010b. Water ice at low to midlatitudes on Mars. J. Geophys. Res. 115, E10001. https://doi.org/10.1029/2010JE003584.

Ward, W.R., 1974. Climatic variations on Mars:1. Astronomical theory of insolation. J. Geophys. Res. 79, 3375-3386. https://doi.org/10.1029/JC079i024p03375.

Ward, W.R., 1979. Present obliquity oscillations of Mars: Fourth-order accuracy in orbitale e and I. J. Geophys. Res. 84, 237-241. https://doi.org/10.1029/JB084iB01p00237. 
1229 Ward, W.R., 1992. Long-term orbital and spin dynamics of Mars, in Mars, edited by H.H. Kieffer 1230 et al., chap. 9, 298-320, Univ. of Ariz. Press, Tucson.

1231

1232 Willmes, M., Reiss, D., Hiesinger, H., Zanetti, M., 2012. Surface age of the ice-dust mantle deposit 1233 in Malea Planum, Mars. Planet. Space Sci. 60, 199-206. https://doi.org/10.1016/j.pss.2011.08.006.

1235

1236 Zuber, M.T. et al., 1992. The Mars Observer laser altimeter investigation. J. Geophys. Res. 97

1237 (E5), 7781-7797. https://doi.org/10.1029/92JE00341.

1238

1239 
Present-day gully activity in Sisyphi Cavi, Mars - Flow-like features and block movements

Jan Raack ${ }^{\mathrm{a}}$, Susan J. Conway ${ }^{\mathrm{b}}$, Thomas Heyer ${ }^{\mathrm{a}}$, Valentin T. Bickel ${ }^{\mathrm{c}, \mathrm{d}}$, Meven Philippe ${ }^{\mathrm{b}}$, Harald Hiesinger $^{a}$, Andreas Johnsson ${ }^{\mathrm{e}}$, Marion Masséb

anstitut für Planetologie, Westfälische Wilhelms-Universität Münster, Wilhelm-Klemm-Str. 10, 48149 Münster, Germany

${ }^{\text {b}}$ Laboratoire de Planétologie et Géodynamique, UMR 6112, CNRS, Université de Nantes, 2 chemin de la Houssinière, BP 92205, 44322 Nantes Cedex 3, France

'Department Planets and Comets, Max-Planck-Institute for Solar System Research, Justus-vonLiebig-Weg 3, 37077 Göttingen, Germany

${ }^{\mathrm{d} D e p a r t m e n t ~ o f ~ E a r t h ~ S c i e n c e s, ~ E T H ~ Z u r i c h, ~ S o n n e g g s t r a s s e ~ 5, ~} 8092$ Zurich, Switzerland

e Department of Earth Sciences, University of Gothenburg, Box 460, Gothenburg SE-405 30, Sweden

\section{Supplementary Material}


Supplementary Table 01: List of all identified active gullies with associated region, specific coordinates, orientation, short description, and time of activity in the study region.

\begin{tabular}{|c|c|c|c|c|c|c|}
\hline Gully & Region & $\begin{array}{l}\text { Lon. (E) / } \\
\text { Lat. (S) }\end{array}$ & $\begin{array}{l}\text { Orienta } \\
\text { tion }\end{array}$ & Description & $\begin{array}{l}\text { Year } \\
\text { active }\end{array}$ & $\begin{array}{l}\text { Time span } \\
\text { between } \\
\text { activity }\end{array}$ \\
\hline Gully 1 & 5 & $\begin{array}{l}1.285^{\circ} / \\
-68.471^{\circ}\end{array}$ & $109^{\circ}$ & $\begin{array}{l}\text { Large dark flow } \\
\text { (Figure 3) }\end{array}$ & MY 33 & 26 sols \\
\hline Gully 2 & 5 & $\begin{array}{l}1.23^{\circ} / \\
-68.481^{\circ}\end{array}$ & $113^{\circ}$ & Dark flow & $\begin{array}{l}\text { MY } 29 \\
\text { MY } 30 \\
\text { MY } 31 \\
\text { MY } 32 \\
\text { MY } 33\end{array}$ & $\begin{array}{l}31 \text { sols } \\
91 \text { sols } \\
27 \text { sols } \\
38 \text { sols } \\
26 \text { sols }\end{array}$ \\
\hline Gully 3 & 5 & $\begin{array}{l}1.443^{\circ} / \\
-68.537^{\circ}\end{array}$ & $352^{\circ}$ & $\begin{array}{l}\text { Large dark flow } \\
\text { (Figure } 5 \text { and Raack } \\
\text { et al., 2015) }\end{array}$ & $\begin{array}{l}\text { MY } 29 \\
\text { MY } 30 \\
\text { MY } 31\end{array}$ & $\begin{array}{l}27 \text { sols } \\
91 \text { sols } \\
17 \text { sols }\end{array}$ \\
\hline Gully 4 & 5 & $\begin{array}{l}1.68^{\circ} / \\
-68.512^{\circ}\end{array}$ & $321^{\circ}$ & Small dark flow & MY 28-31 & 2012 sols \\
\hline Gully 5 & 10 & $\begin{array}{l}-13.84^{\circ} / \\
-69.48^{\circ}\end{array}$ & $232^{\circ}$ & Small flow & MY 32 & 42 sols \\
\hline Gully 6 & 10 & $\begin{array}{l}-13.835^{\circ} / \\
-69.481^{\circ}\end{array}$ & $200^{\circ}$ & Very small changes & $\begin{array}{l}\text { MY } 31 \\
\text { MY } 32 \\
\text { MY } 33\end{array}$ & $\begin{array}{l}33 \text { sols } \\
42 \text { sols } \\
65 \text { sols }\end{array}$ \\
\hline Gully 7 & 10 & $\begin{array}{l}-13.826^{\circ} / \\
-69.493^{\circ}\end{array}$ & $224^{\circ}$ & $\begin{array}{l}\text { Very small changes } \\
\text { plus block } \\
\text { movements }\end{array}$ & $\begin{array}{l}\text { MY } 31^{\dagger} \\
\text { MY } 31^{\dagger} \\
\text { MY } 33\end{array}$ & $\begin{array}{l}65 \text { sols } \\
16 \text { sols } \\
54 \text { sols }\end{array}$ \\
\hline Gully 8 & 10 & $\begin{array}{l}-13.786^{\circ} / \\
-69.512^{\circ}\end{array}$ & $198^{\circ}$ & Very small changes & $\begin{array}{l}\text { MY } 31 \\
\text { MY } 32\end{array}$ & $\begin{array}{l}33 \text { sols } \\
133 \text { sols }\end{array}$ \\
\hline Gully 9 & 10 & $\begin{array}{l}-13.71^{\circ} / \\
-69.525^{\circ}\end{array}$ & $196^{\circ}$ & $\begin{array}{l}\text { Several small } \\
\text { changes }\end{array}$ & MY 33 & 44 sols \\
\hline $\begin{array}{l}\text { Gully } \\
10\end{array}$ & 10 & $\begin{array}{l}-13.698^{\circ} / \\
-69.527^{\circ}\end{array}$ & $208^{\circ}$ & Some small changes & $\begin{array}{l}\text { MY } 32 \\
\text { MY } 33\end{array}$ & $\begin{array}{l}42 \mathrm{sols} \\
44 \mathrm{sols}\end{array}$ \\
\hline $\begin{array}{l}\text { Gully } \\
11\end{array}$ & 11 & $\begin{array}{l}1.2^{\circ} / \\
-70.92^{\circ}\end{array}$ & $216^{\circ}$ & $\begin{array}{l}\text { Largest activity (see } \\
\text { Figure 4) }\end{array}$ & MY 32-33 & 673 sols \\
\hline $\begin{array}{l}\text { Gully } \\
12\end{array}$ & 11 & $\begin{array}{l}1.224^{\circ} / \\
-70.92^{\circ}\end{array}$ & $229^{\circ}$ & $\begin{array}{l}\text { Very small changes } \\
\text { plus large block } \\
\text { movement }{ }^{\dagger} \text { (see } \\
\text { Figure } 7 \text { ) }\end{array}$ & $\begin{array}{l}\text { MY 31-32 } \\
\text { MY 32-33 }\end{array}$ & $\begin{array}{l}673 \text { sols } \\
673 \text { sols }\end{array}$ \\
\hline $\begin{array}{l}\text { Gully } \\
13\end{array}$ & 11 & $\begin{array}{l}1.392^{\circ} / \\
-70.949^{\circ}\end{array}$ & $194^{\circ}$ & Medium changes & MY 32-33 & 673 sols \\
\hline $\begin{array}{l}\text { Gully } \\
14\end{array}$ & 12 & $\begin{array}{l}4.292^{\circ} / \\
-70.678^{\circ}\end{array}$ & $305^{\circ}$ & Small dark flow & $\begin{array}{l}\text { MY 32-33 } \\
\text { MY } 33\end{array}$ & $\begin{array}{l}575 \text { sols } \\
166 \text { sols }\end{array}$ \\
\hline $\begin{array}{l}\text { Gully } \\
15\end{array}$ & 12 & $\begin{array}{l}4.21^{\circ} / \\
-70.74^{\circ}\end{array}$ & $297^{\circ}$ & Medium dark flow & MY 29-32 & 2160 sols \\
\hline
\end{tabular}




\begin{tabular}{|c|c|c|c|c|c|c|}
\hline $\begin{array}{l}\text { Gully } \\
16\end{array}$ & 14 & $\begin{array}{l}3.161^{\circ} / \\
-71.203^{\circ}\end{array}$ & $234^{\circ}$ & Small changes & MY 32-33 & 1400 sols \\
\hline $\begin{array}{l}\text { Gully } \\
17\end{array}$ & 14 & $\begin{array}{l}3.186^{\circ} / \\
-71,204^{\circ}\end{array}$ & $247^{\circ}$ & Very small changes & MY 30-31 & 708 sols \\
\hline $\begin{array}{l}\text { Gully } \\
18\end{array}$ & 14 & $\begin{array}{l}3.205^{\circ} / \\
-71,212^{\circ}\end{array}$ & $260^{\circ}$ & Small changes & MY 28-33 & 3357 sols \\
\hline $\begin{array}{l}\text { Gully } \\
19\end{array}$ & 14 & $\begin{array}{l}3.17^{\circ} / \\
-71.288^{\circ} \\
\end{array}$ & $301^{\circ}$ & Very small dark flow & MY 28-30 & 1163 sols \\
\hline $\begin{array}{l}\text { Gully } \\
20\end{array}$ & 18 & $\begin{array}{l}2.237^{\circ} / \\
-72.159^{\circ}\end{array}$ & $301^{\circ}$ & Medium changes & MY 29-32 & 2032 sols \\
\hline $\begin{array}{l}\text { Gully } \\
21\end{array}$ & 18 & $\begin{array}{l}2.206^{\circ} / \\
-72.17^{\circ}\end{array}$ & $316^{\circ}$ & Block movement & MY 29-32 & 2032 sols \\
\hline $\begin{array}{l}\text { Gully } \\
22\end{array}$ & 18 & $\begin{array}{l}2.203^{\circ} / \\
-72.17^{\circ}\end{array}$ & $315^{\circ}$ & Block movement & MY 29-32 & 2032 sols \\
\hline $\begin{array}{l}\text { Gully } \\
23\end{array}$ & 18 & $\begin{array}{l}2.193^{\circ} / \\
-72.175^{\circ}\end{array}$ & $325^{\circ}$ & Block movement & MY 32-33 & 634 sols \\
\hline $\begin{array}{l}\text { Gully } \\
24\end{array}$ & 18 & $\begin{array}{l}2.189^{\circ} / \\
-72.176^{\circ} \\
\end{array}$ & $262^{\circ}$ & Block movement & MY 32-33 & 634 sols \\
\hline $\begin{array}{l}\text { Gully } \\
25\end{array}$ & 18 & $\begin{array}{l}2.19^{\circ} / \\
-72.177^{\circ}\end{array}$ & $300^{\circ}$ & Block movement & MY 29-32 & 2032 sols \\
\hline $\begin{array}{l}\text { Gully } \\
26\end{array}$ & 18 & $\begin{array}{l}2.184^{\circ} / \\
-72.178^{\circ} \\
\end{array}$ & $300^{\circ}$ & Block movement & MY 29-32 & 2032 sols \\
\hline $\begin{array}{l}\text { Gully } \\
27\end{array}$ & 20 & $\begin{array}{l}3.724^{\circ} / \\
-72.172^{\circ} \\
\end{array}$ & $258^{\circ}$ & Block movement & MY 31-33 & 2688 sols \\
\hline $\begin{array}{l}\text { Gully } \\
28\end{array}$ & 20 & $\begin{array}{l}3.724^{\circ} / \\
-72.173^{\circ} \\
\end{array}$ & $222^{\circ}$ & Block movement & MY 29-30 & 709 sols \\
\hline $\begin{array}{l}\text { Gully } \\
29\end{array}$ & 20 & $\begin{array}{l}3.725^{\circ} / \\
-72.175^{\circ} \\
\end{array}$ & $293^{\circ}$ & Block movement & MY 29-30 & 709 sols \\
\hline $\begin{array}{l}\text { Gully } \\
30\end{array}$ & 20 & $\begin{array}{l}3.745^{\circ} / \\
-72.182^{\circ} \\
\end{array}$ & $209^{\circ}$ & Block movement & MY 29-30 & 613 sols \\
\hline $\begin{array}{l}\text { Gully } \\
31\end{array}$ & 20 & $\begin{array}{l}3.898^{\circ} / \\
-72.244^{\circ} \\
\end{array}$ & $255^{\circ}$ & Small changes & $\begin{array}{l}\text { MY 29-30 } \\
\text { MY 30-33 }\end{array}$ & $\begin{array}{l}709 \text { sols } \\
1969 \text { sols } \\
\end{array}$ \\
\hline $\begin{array}{l}\text { Gully } \\
32\end{array}$ & 20 & $\begin{array}{l}3.909^{\circ} / \\
-72.249^{\circ}\end{array}$ & $224^{\circ}$ & $\begin{array}{l}\text { Block movement (in } \\
\text { same gully, but } \\
\text { different places) }\end{array}$ & MY 30-33 & 1969 sols \\
\hline $\begin{array}{l}\text { Gully } \\
33\end{array}$ & 20 & $\begin{array}{l}3.914^{\circ} / \\
-72.248^{\circ}\end{array}$ & $236^{\circ}$ & $\begin{array}{l}\text { Block movement (in } \\
\text { same gully, but } \\
\text { different places) }\end{array}$ & MY 30-33 & 1969 sols \\
\hline $\begin{array}{l}\text { Gully } \\
34\end{array}$ & 20 & $\begin{array}{l}3.924^{\circ} / \\
-72.248^{\circ} \\
\end{array}$ & $249^{\circ}$ & $\begin{array}{l}\text { Small changes plus } \\
\text { block movements }\end{array}$ & MY 30-33 & 1969 sols \\
\hline $\begin{array}{l}\text { Gully } \\
35\end{array}$ & 20 & $\begin{array}{l}3.943^{\circ} / \\
-72.253^{\circ}\end{array}$ & $229^{\circ}$ & Block movement & MY 29-30 & 709 sols \\
\hline
\end{tabular}


Supplementary Table 02: Slope angles of all investigated gullies in region 5 and 11 from the beginning of their alcoves, through their channels, above their aprons until the end of the general slope (Figure 8). Slope angles are reported as calculated over $100 \mathrm{~m}$-long segments of the gully length. The last row of the table shows the overall average angle of the slope following the path of individual gullies. Active gullies are marked in bold.

\begin{tabular}{|c|c|c|c|c|c|c|c|c|c|c|c|c|c|c|c|c|}
\hline \multirow{2}{*}{$\begin{array}{l}\text { Length } \\
\text { (m) }\end{array}$} & \multicolumn{6}{|c|}{ Region 11} & \multicolumn{10}{|c|}{ Region 5} \\
\hline & $\mathbf{A}$ & B & $\mathrm{C}$ & $\mathrm{D}$ & $E$ & $\mathbf{F}$ & $\mathbf{G}$ & $\mathrm{H}$ & $\mathrm{I}$ & $\mathrm{J}$ & $\mathrm{K}$ & $\mathbf{L}$ & $\mathrm{M}$ & $\mathbf{N}$ & $\mathrm{O}$ & $\mathrm{P}$ \\
\hline 100 & $29^{\circ}$ & $\mathbf{3 3}^{\circ}$ & $39^{\circ}$ & $43^{\circ}$ & $36^{\circ}$ & $37^{\circ}$ & $\mathbf{3 8}^{\circ}$ & $36^{\circ}$ & $34^{\circ}$ & $36^{\circ}$ & $35^{\circ}$ & $15^{\circ}$ & $35^{\circ}$ & $\mathbf{5 0}^{\circ}$ & $38^{\circ}$ & $42^{\circ}$ \\
\hline 200 & $36^{\circ}$ & $45^{\circ}$ & $34^{\circ}$ & $38^{\circ}$ & $35^{\circ}$ & $32^{\circ}$ & $28^{\circ}$ & $29^{\circ}$ & $27^{\circ}$ & $26^{\circ}$ & $27^{\circ}$ & $15^{\circ}$ & $37^{\circ}$ & $44^{\circ}$ & $38^{\circ}$ & $31^{\circ}$ \\
\hline 300 & $38^{\circ}$ & $34^{\circ}$ & $28^{\circ}$ & $30^{\circ}$ & $37^{\circ}$ & $37^{\circ}$ & $20^{\circ}$ & $20^{\circ}$ & $23^{\circ}$ & $29^{\circ}$ & $20^{\circ}$ & $13^{\circ}$ & $23^{\circ}$ & $\mathbf{2 3}^{\circ}$ & $33^{\circ}$ & $22^{\circ}$ \\
\hline 400 & $27^{\circ}$ & $25^{\circ}$ & $22^{\circ}$ & $24^{\circ}$ & $23^{\circ}$ & $26^{\circ}$ & $18^{\circ}$ & $18^{\circ}$ & $20^{\circ}$ & $20^{\circ}$ & $17^{\circ}$ & $13^{\circ}$ & $15^{\circ}$ & $18^{\circ}$ & $22^{\circ}$ & $17^{\circ}$ \\
\hline 500 & $21^{\circ}$ & $21^{\circ}$ & $19^{\circ}$ & $19^{\circ}$ & $19^{\circ}$ & $14^{\circ}$ & $16^{\circ}$ & $15^{\circ}$ & $18^{\circ}$ & $19^{\circ}$ & $16^{\circ}$ & $12^{\circ}$ & $14^{\circ}$ & $14^{\circ}$ & $15^{\circ}$ & $16^{\circ}$ \\
\hline 600 & $17^{\circ}$ & $16^{\circ}$ & $16^{\circ}$ & $12^{\circ}$ & $15^{\circ}$ & $12^{\circ}$ & $15^{\circ}$ & $14^{\circ}$ & $19^{\circ}$ & $15^{\circ}$ & $15^{\circ}$ & $11^{\circ}$ & $12^{\circ}$ & $14^{\circ}$ & $15^{\circ}$ & $12^{\circ}$ \\
\hline 700 & $15^{\circ}$ & $13^{\circ}$ & $12^{\circ}$ & $10^{\circ}$ & $12^{\circ}$ & $16^{\circ}$ & $16^{\circ}$ & $16^{\circ}$ & $15^{\circ}$ & $16^{\circ}$ & $16^{\circ}$ & $11^{\circ}$ & $11^{\circ}$ & $13^{\circ}$ & $13^{\circ}$ & $15^{\circ}$ \\
\hline 800 & $14^{\circ}$ & $12^{\circ}$ & $11^{\circ}$ & $11^{\circ}$ & $12^{\circ}$ & $11^{\circ}$ & $16^{\circ}$ & $16^{\circ}$ & $14^{\circ}$ & $15^{\circ}$ & $14^{\circ}$ & $12^{\circ}$ & $11^{\circ}$ & $13^{\circ}$ & $16^{\circ}$ & $15^{\circ}$ \\
\hline 900 & $11^{\circ}$ & $11^{\circ}$ & $11^{\circ}$ & $12^{\circ}$ & $11^{\circ}$ & $12^{\circ}$ & $14^{\circ}$ & $15^{\circ}$ & $15^{\circ}$ & $19^{\circ}$ & $15^{\circ}$ & $11^{\circ}$ & $12^{\circ}$ & $13^{\circ}$ & $18^{\circ}$ & $15^{\circ}$ \\
\hline 1000 & $13^{\circ}$ & $13^{\circ}$ & $12^{\circ}$ & $12^{\circ}$ & $14^{\circ}$ & $10^{\circ}$ & $13^{\circ}$ & $16^{\circ}$ & $15^{\circ}$ & $14^{\circ}$ & $14^{\circ}$ & $12^{\circ}$ & $12^{\circ}$ & $12^{\circ}$ & $19^{\circ}$ & $14^{\circ}$ \\
\hline 1100 & $10^{\circ}$ & $12^{\circ}$ & $11^{\circ}$ & $10^{\circ}$ & $11^{\circ}$ & $11^{\circ}$ & $14^{\circ}$ & $14^{\circ}$ & $15^{\circ}$ & $14^{\circ}$ & $14^{\circ}$ & $11^{\circ}$ & $10^{\circ}$ & $11^{\circ}$ & $14^{\circ}$ & $13^{\circ}$ \\
\hline 1200 & $12^{\circ}$ & $10^{\circ}$ & $11^{\circ}$ & $9^{\circ}$ & $9^{\circ}$ & $10^{\circ}$ & $15^{\circ}$ & $13^{\circ}$ & $16^{\circ}$ & $13^{\circ}$ & $20^{\circ}$ & $11^{\circ}$ & $9^{\circ}$ & $10^{\circ}$ & $13^{\circ}$ & $12^{\circ}$ \\
\hline 1300 & & $11^{\circ}$ & $11^{\circ}$ & $12^{\circ}$ & $12^{\circ}$ & $9^{\circ}$ & $14^{\circ}$ & $13^{\circ}$ & $15^{\circ}$ & $13^{\circ}$ & $13^{\circ}$ & $10^{\circ}$ & $11^{\circ}$ & $10^{\circ}$ & $12^{\circ}$ & $12^{\circ}$ \\
\hline 1400 & & $11^{\circ}$ & $11^{\circ}$ & $10^{\circ}$ & $8^{\circ}$ & $9^{\circ}$ & $12^{\circ}$ & $13^{\circ}$ & $14^{\circ}$ & $12^{\circ}$ & $14^{\circ}$ & $11^{\circ}$ & $10^{\circ}$ & $11^{\circ}$ & $12^{\circ}$ & $11^{\circ}$ \\
\hline 1500 & & $11^{\circ}$ & $12^{\circ}$ & $10^{\circ}$ & $10^{\circ}$ & $10^{\circ}$ & $13^{\circ}$ & $13^{\circ}$ & $14^{\circ}$ & $13^{\circ}$ & $12^{\circ}$ & $10^{\circ}$ & $11^{\circ}$ & $11^{\circ}$ & $11^{\circ}$ & $11^{\circ}$ \\
\hline 1600 & & $12^{\circ}$ & $9^{\circ}$ & $9^{\circ}$ & $10^{\circ}$ & $9^{\circ}$ & $11^{\circ}$ & $12^{\circ}$ & $13^{\circ}$ & $13^{\circ}$ & $13^{\circ}$ & $10^{\circ}$ & $10^{\circ}$ & $10^{\circ}$ & $10^{\circ}$ & $10^{\circ}$ \\
\hline 1700 & & $9^{\circ}$ & $14^{\circ}$ & $11^{\circ}$ & $11^{\circ}$ & $10^{\circ}$ & $10^{\circ}$ & $11^{\circ}$ & $13^{\circ}$ & $13^{\circ}$ & $9^{\circ}$ & $10^{\circ}$ & $10^{\circ}$ & $11^{\circ}$ & $10^{\circ}$ & $10^{\circ}$ \\
\hline 1800 & & $11^{\circ}$ & $7^{\circ}$ & $10^{\circ}$ & $11^{\circ}$ & $10^{\circ}$ & $11^{\circ}$ & $9^{\circ}$ & $13^{\circ}$ & $12^{\circ}$ & $9^{\circ}$ & $9^{\circ}$ & $10^{\circ}$ & $11^{\circ}$ & $10^{\circ}$ & $11^{\circ}$ \\
\hline 1900 & & $11^{\circ}$ & $11^{\circ}$ & $10^{\circ}$ & $10^{\circ}$ & $10^{\circ}$ & $10^{\circ}$ & $9^{\circ}$ & $12^{\circ}$ & $11^{\circ}$ & $7^{\circ}$ & $8^{\circ}$ & $9^{\circ}$ & $10^{\circ}$ & $9^{\circ}$ & $10^{\circ}$ \\
\hline 2000 & & $9^{\circ}$ & $12^{\circ}$ & $10^{\circ}$ & $11^{\circ}$ & $11^{\circ}$ & $13^{\circ}$ & $13^{\circ}$ & $11^{\circ}$ & $19^{\circ}$ & $2^{\circ}$ & $8^{\circ}$ & $7^{\circ}$ & $9^{\circ}$ & $7^{\circ}$ & $9^{\circ}$ \\
\hline 2100 & & $9^{\circ}$ & $11^{\circ}$ & $9^{\circ}$ & $10^{\circ}$ & $8^{\circ}$ & $19^{\circ}$ & $18^{\circ}$ & $10^{\circ}$ & $3^{\circ}$ & & $6^{\circ}$ & $5^{\circ}$ & $8^{\circ}$ & & $8^{\circ}$ \\
\hline 2200 & & $10^{\circ}$ & $8^{\circ}$ & $10^{\circ}$ & $9^{\circ}$ & $\mathbf{8}^{\circ}$ & $25^{\circ}$ & $25^{\circ}$ & $8^{\circ}$ & & & $\mathbf{0}^{\circ}$ & $3^{\circ}$ & & & $8^{\circ}$ \\
\hline 2300 & & $10^{\circ}$ & $9^{\circ}$ & $10^{\circ}$ & $10^{\circ}$ & $9^{\circ}$ & & & $5^{\circ}$ & & & $\mathbf{0}^{\circ}$ & $6^{\circ}$ & & & $7^{\circ}$ \\
\hline 2400 & & & $9^{\circ}$ & $10^{\circ}$ & $8^{\circ}$ & $9^{\circ}$ & & & & & & & $13^{\circ}$ & & & \\
\hline 2500 & & & $8^{\circ}$ & $9^{\circ}$ & $9^{\circ}$ & $\mathbf{8}^{\circ}$ & & & & & & & $12^{\circ}$ & & & \\
\hline 2600 & & & $6^{\circ}$ & $9^{\circ}$ & $7^{\circ}$ & $\mathbf{8}^{\circ}$ & & & & & & & & & & \\
\hline 2700 & & & $4^{\circ}$ & $6^{\circ}$ & $6^{\circ}$ & $7^{\circ}$ & & & & & & & & & & \\
\hline 2800 & & & & $4^{\circ}$ & $3^{\circ}$ & $6^{\circ}$ & & & & & & & & & & \\
\hline 2900 & & & & & & $5^{\circ}$ & & & & & & & & & & \\
\hline & $20^{\circ}$ & $16^{\circ}$ & $14^{\circ}$ & $14^{\circ}$ & $14^{\circ}$ & $13^{\circ}$ & $16^{\circ}$ & $16^{\circ}$ & $16^{\circ}$ & $16^{\circ}$ & $16^{\circ}$ & $10^{\circ}$ & $13^{\circ}$ & $16^{\circ}$ & $17^{\circ}$ & $14^{\circ}$ \\
\hline
\end{tabular}


Supplementary Table 03: List of the HiRISE image pairs used for DTM generation, including their spatial resolution and their mean intersection error as a measure for DTM quality. Some of the listed DTMs have been used to orthorectify the HiRISE imagery used for DIC.

\begin{tabular}{|l|l|l|l|}
\hline Timeframe & HiRISE pair & $\begin{array}{l}\text { DTM spatial } \\
\text { resolution (m/pix) }\end{array}$ & $\begin{array}{l}\text { Mean intersection } \\
\text { error (m) }\end{array}$ \\
\hline $2007-2011$ & $\begin{array}{l}\text { ESP_023290_1090 } \\
\text { PSP_005621_1090 }\end{array}$ & 2 & 0.62 \\
\hline $2007-2016$ & $\begin{array}{l}\text { ESP_048608_1090 } \\
\text { PSP_005621_1090 }\end{array}$ & 1 & 0.25 \\
\hline $2013-2015$ & $\begin{array}{l}\text { ESP_030859_1090 } \\
\text { ESP_039747_1090 }\end{array}$ & 3 & 0.87 \\
\hline $2015-2016$ & $\begin{array}{l}\text { ESP_039747_1090 } \\
\text { ESP_048608_1090 }\end{array}$ & 0.5 & 0.48 \\
\hline
\end{tabular}

